\title{
Analysis of Molecular Networks in the Cerebellum in Chronic Schizophrenia: Modulation by Early Postnatal Life Stressors in Murine Models
}

\author{
América Vera-Montecinos ${ }^{1}$, Ricard Rodríguez-Mias ${ }^{2}$, Karina S. MacDowell ${ }^{3,4} \oplus$, Borja García-Bueno ${ }^{3,4}$, \\ Álvaro G. Bris ${ }^{3,4}$, Javier R. Caso ${ }^{3,4}\left(\mathbb{D}\right.$, Judit Villén ${ }^{2}(\mathbb{C}$ and Belén Ramos $1,4,5,6,7, * \mathbb{C}$
}

Citation: Vera-Montecinos, A.; Rodríguez-Mias, R.; MacDowell, K.S.; García-Bueno, B.; Bris, Á.G.; Caso,

J.R.; Villén, J.; Ramos, B. Analysis of Molecular Networks in the Cerebellum in Chronic Schizophrenia: Modulation by Early Postnatal Life Stressors in Murine Models. Int. J. Mol. Sci. 2021, 22, 10076. https:// doi.org/10.3390/ijms221810076

Academic Editor: Philippe De Deurwaerdère

Received: 31 May 2021

Accepted: 9 September 2021

Published: 17 September 2021

Publisher's Note: MDPI stays neutral with regard to jurisdictional claims in published maps and institutional affiliations.

Copyright: (C) 2021 by the authors Licensee MDPI, Basel, Switzerland. This article is an open access article distributed under the terms and conditions of the Creative Commons Attribution (CC BY) license (https:// creativecommons.org/licenses/by/ $4.0 /)$.
1 Psiquiatria Molecular, Institut de Recerca Sant Joan de Déu, Santa Rosa 39-57, 08950 Esplugues de Llobregat, Spain; ajvera@fsjd.org

2 Department of Genome Sciences, School of Medicine, University of Washington, 3720 15th Ave NE, Seattle, WA 98195, USA; rr65@uw.edu (R.R.-M.); jvillen@uw.edu (J.V.)

3 Departamento de Farmacología y Toxicología, Facultad de Medicina, Universidad Complutense de Madrid, Instituto de Investigación Sanitaria Hospital 12 de Octubre (Imas12), Instituto Universitario de Investigación en Neuroquímica IUIN-UCM, Avda. Complutense s/n, 28040 Madrid, Spain; karinmac@ucm.es (K.S.M.); bgbueno@med.ucm.es (B.G.-B.); agbris@ucm.es (Á.G.B.); jrcaso@med.ucm.es (J.R.C.)

4 Centro de Investigación Biomédica en Red de Salud Mental, CIBERSAM (Biomedical Network Research Center of Mental Health), Institute of Health Carlos III, 28029 Madrid, Spain

5 Parc Sanitari Sant Joan de Déu, Doctor Antoni Pujadas 42, 08830 Sant Boi de Llobregat, Spain

6 Faculty of Medicine, University of Vic_-Central University of Catalonia, 08500 Vic, Spain

7 Departamento de Bioquímica i Biología Molecular, Facultat de Medicina, Universitat Autònoma de Barcelona, 08193 Bellaterra, Spain

* Correspondence: belen.ramos@sjd.es; Tel.: +34-(93)-600-9452; Fax: +34-(93)-600-97711

Abstract: Despite the growing importance of the cerebellum as a region highly vulnerable to accumulating molecular errors in schizophrenia, limited information is available regarding altered molecular networks with potential therapeutic targets. To identify altered networks, we conducted one-shot liquid chromatography-tandem mass spectrometry in postmortem cerebellar cortex in schizophrenia and healthy individuals followed by bioinformatic analysis (PXD024937 identifier in ProteomeXchange repository). A total of 108 up-regulated proteins were enriched in stress-related proteins, half of which were also enriched in axonal cytoskeletal organization and vesicle-mediated transport. A total of 142 down-regulated proteins showed an enrichment in proteins involved in mitochondrial disease, most of which were also enriched in energy-related biological functions. Network analysis identified a mixed module of mainly axonal-related pathways for up-regulated proteins with a high number of interactions for stress-related proteins. Energy metabolism and neutrophil degranulation modules were found for down-regulated proteins. Further, two double-hit postnatal stress murine models based on maternal deprivation combined with social isolation or chronic restraint stress were used to investigate the most robust candidates of generated networks. CLASP1 from the axonal module in the model of maternal deprivation was combined with social isolation, while YWHAZ was not altered in either model. METTL7A from the degranulation pathway was reduced in both models and was identified as altered also in previous gene expression studies, while NDUFB9 from the energy network was reduced only in the model of maternal deprivation combined with social isolation. This work provides altered stress- and mitochondrial disease-related proteins involved in energy, immune and axonal networks in the cerebellum in schizophrenia as possible novel targets for therapeutic interventions and suggests that METTL7A is a possible relevant altered stress-related protein in this context.

Keywords: proteomics; postmortem brain; pathways; networks; schizophrenia 


\section{Introduction}

Schizophrenia (SZ) is a complex polygenic psychiatric disorder involving dysregulation of multiples pathways [1] with an estimated prevalence up to $1 \%$ in the general population [2] and a high heritability up to 79\% [3]. Although the etiology of SZ is not fully understood, several hypotheses have been postulated. The neurodevelopmental hypothesis proposes two critical periods of neurodevelopmental vulnerability, namely early life and adolescence. An environmental double-hit in these phases in a genetically predisposed individual is required for the emergence of the disease [4,5]. Based on this hypothesis, cumulative damage in different molecular pathways required for the early development of the central nervous system could contribute to the failure of axonal assembly connections and normal synaptic transmission, which could remain latent until adolescence [6]. In this phase of life, an additional stressor such as psychosocial stress could impact upon these vulnerable pathologic neural circuits, leading to altered functioning of synaptic responses and the emergence of symptoms [7-9]. To study the role that psychosocial stress may play in SZ, different animal models have been developed that include prenatal or perinatal stress. Prenatal models may include different types of stressors such as restraint of movement together with water and/or food deprivation [9] and foot-shocks [10] to the mother. Supporting these animal models are other findings from animal experiments that showed that prenatal exposure to stressors leads to learning deficits [11,12]. Furthermore, a study found that post-weaning social isolation induces altered adult behavior as a result of hyperactivity of the hypothalamic-pituitary-adrenal axis [13]. Another animal model used to understand the origin of SZ is the double-hit model in which two hits are required for the emergence of this disorder, the first hit occurring in the prenatal or perinatal phase and a second during adolescence [14,15]. According to the developmental hypothesis for SZ $[5,16]$, the etiological validity is satisfied with these models as they are based on stressors during developmental phase in the origin. The face and construct validity of these models is demonstrated through several behavioral test analyses that have shown SZ-like symptoms in these models, including positive symptoms (deficits in prepulse inhibition and anxiety), negative symptoms (reduced sociability and novelty preference) and general psychopathological symptoms (innate anxiety-like behavior, increased locomotor activity and impaired working memory). Moreover, these models also display SZ-like neurobiological characteristics, such as biochemical alterations in glutamatergic and monoaminergic pathways, neuroinflammatory reactions and oxidative/nitrosative stress responses [17].There is emerging accumulating evidence of the role of the cerebellum in stress-related psychiatric conditions [18]. In the context of schizophrenia, psychosocial stress mediated by cortisol is found to be related to decreased blood flow in the cerebellum and an impairment of a number of cognitive functions [19]. In schizophrenia patients, higher cumulative stress has been found to be associated with higher connectivity between the hippocampus and the cerebellum [20]. Another study in siblings of schizophrenia patients reported increased connectivity between the executive control network and the cerebellum after stress [21]. Further high childhood trauma has been shown to increase the relationship between cortisol reactivity and cerebellum activity in schizophrenia but not in bipolar disorder [22]. In this context, for correct emotional processing, high cortisol reactivity is necessary. These authors show low cortisol reactivity in schizophrenia subjects, which could be associated with high activation in the left cerebellar lobules IV and V, areas that contribute to recognizing and discriminating emotional faces. Thus, altered cortisol reactivity could generate disruption in cerebellar-dependent emotional processing in schizophrenia subjects. Psychosocial stress has been shown to be associated with altered resting-state functional connectivity of the cerebellum in participants with high levels of schizotypal traits [23], suggesting that the cerebellum is a brain area susceptible to psychosocial stress and highly vulnerable in schizophrenia. The cerebellum integrates input signals from different brain areas and is connected to stress-response regions (e.g., hypothalamus, amygdala) that have been shown to be affected in schizophrenia. The cerebellum has the molecular machinery needed to process stress mediators [18] and is the last region 
to complete neuronal progenitor division, neuronal migration and pruning of dendritic arborization [24]. This lengthy maturation phase of the cerebellum makes this area highly vulnerable to stress-induced error accumulation during development, which may have a significant impact in SZ. Thus, the cerebellum constitutes an attractive area to study as a possible reservoir of failures in multiple pathways through development and during postnatal life.

Despite the growing importance of the cerebellum as a stress target region highly vulnerable to accumulating molecular stress-induced errors in schizophrenia, only a few recent studies have investigated global mRNA [25] or proteomic alterations in this region [26,27]. The main aim of our study was to identify altered protein networks in the cerebellum with potential therapeutic targets for schizophrenia. To achieve this, we compared the proteomic profile in postmortem lateral cerebellar cortex of individuals with chronic schizophrenia ( $n=12)$ and control healthy subjects $(n=14)$ that we obtained using single shot liquid chromatography-tandem mass spectrometry analysis (Figure 1A). Furthermore, we also investigated robustly altered proteins of the identified altered protein networks in two separate double-hit postnatal stress murine models induced by maternal deprivation combined with an additional stressor (social isolation or chronic restraint stress). 


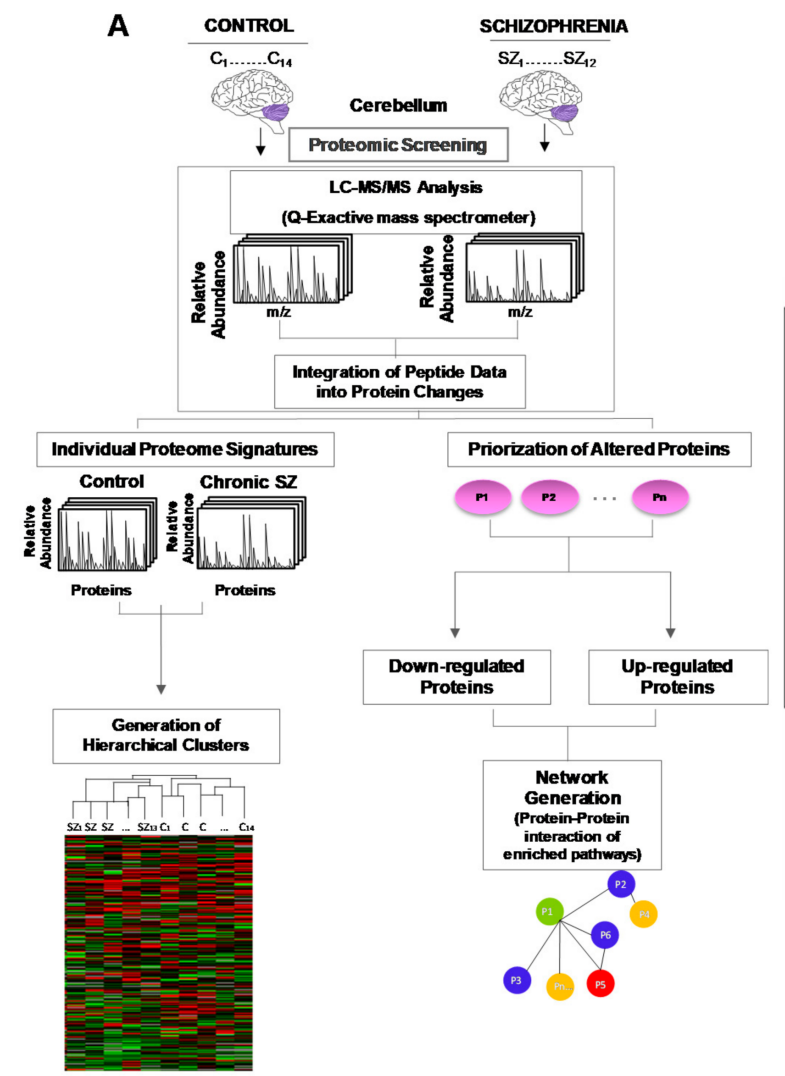

B

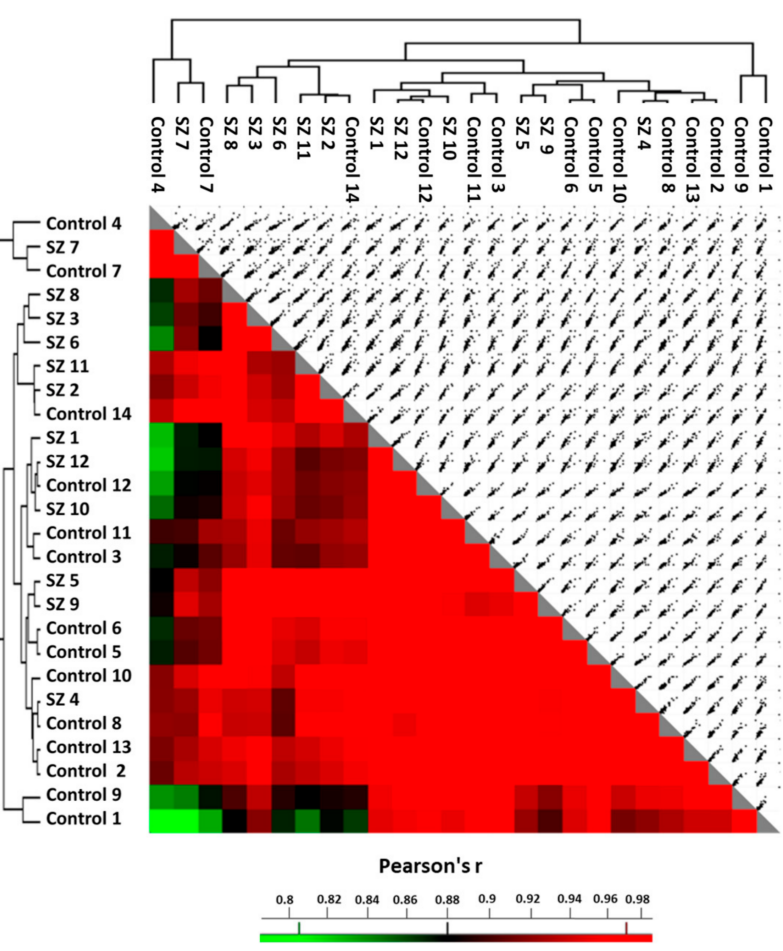

C
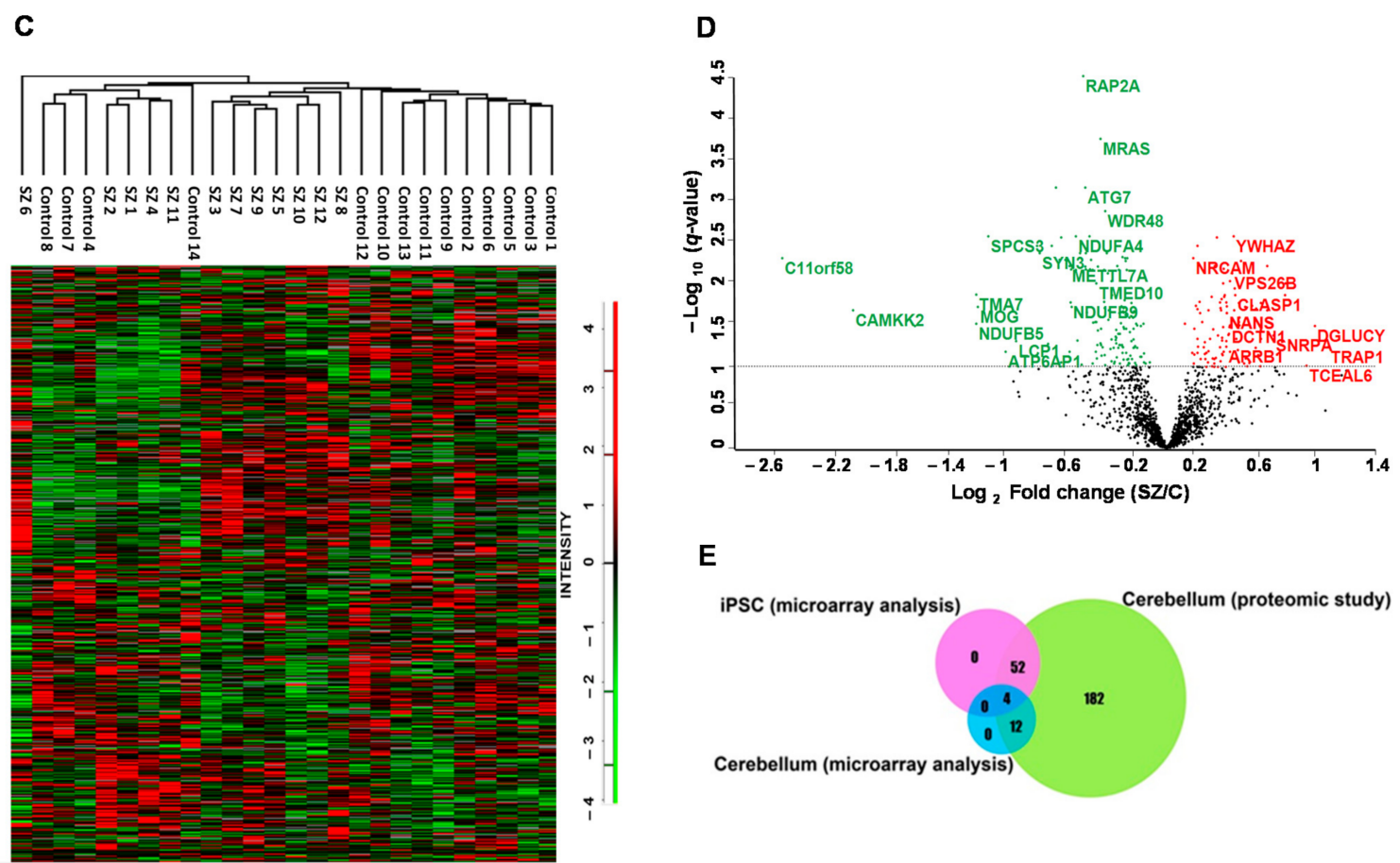

E

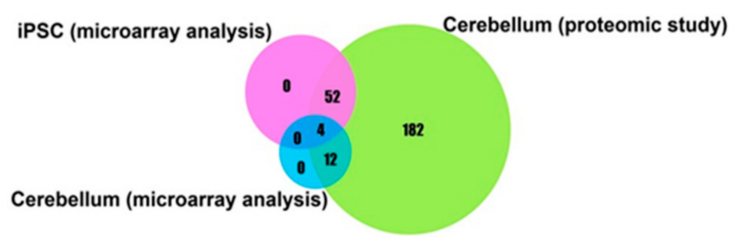

Figure 1. Quantitative proteomic analysis in the cerebellum in chronic schizophrenia. (A) Experimental design for proteomic analysis to identify altered pathways in schizophrenia. Protein lysates from the postmortem cerebellum of control C $(n=14)$ and chronic schizophrenia (SZ) patients $(n=12)$ were processed as described. The peptides were separated and analyzed by liquid chromatography (LC) coupled with tandem mass spectrometry. The relative fold change of peptides was integrated into protein changes. The individual protein signatures for each case and control were used to generate hierarchical clusters. The prioritization of altered proteins (P1-Pn represents generic proteins) in SZ was obtained by comparing protein 
fold changes between control and SZ groups (significant proteins adjusted using an FDR of 0.1). We performed two analyses for these altered proteins in SZ: (i) unsupervised hierarchical clustering analysis generated from quantified proteins in 12 SZ and 14 healthy control samples of postmortem cerebellum; and (ii) generation of networks from significantly enriched pathways by protein-protein interaction. These analyses were performed using Perseus and String, respectively. (B) A correlation matrix for 1474 quantified proteins across sample pairs. (C) Unsupervised hierarchical clustering analysis was obtained with matrix processing according to the Euclidean distance and z-score aggregation method. Protein profiles were generated from 1474 quantified proteins in $12 \mathrm{SZ}$ and 14 healthy control samples of postmortem cerebellum and were clustered according to the z-score and displayed as a heat map. Green color clusters represent under-expressed proteins. Red color clusters represent overexpressed proteins. (D) Volcano plot of the $-\log _{10}$ q-value (adjusted $p$-value; FDR ( $\leq 0.1$ )) versus the $\log _{2}$ fold change in the cerebellum in SZ relative to healthy control. SZ, schizophrenia; C, control. Up-regulated and down-regulated significant proteins are represented in red and green, respectively. The grey line shows the FDR threshold. (E) Venn diagram showing overlap between proteins previously reported in SZ through gene expression analysis obtained from SZDB (human cerebellum and iPSC) and our proteomic study in cerebellum.

\section{Results}

\subsection{Quantitative Proteomic Analyses in Cerebellum in Chronic Schizophrenia}

To identify altered proteins related to SZ, we performed a proteomic analysis of human cerebellar lateral cortex protein extracts from 12 male SZ patients and 14 control individuals matched for gender, age and postmortem delay (PMD). No differences were observed between the SZ and control groups for any demographic or tissue-related variables (Table S1). Using mass spectrometry, a total of 2578 proteins were quantified. A total of 1474 proteins $(57 \%)$ were quantified in at least seven individuals per group and used for subsequent bioinformatics analyses (Supplementary Dataset S1); $97.8 \%$ of the proteins were identified with two or more peptides and $46.5 \%$ with five or more peptides. For the individual proteome signature analyses, we examined the similarity of the individual proteome through a correlation matrix. To assess the similarity between the proteomes of the different individuals, we calculated Pearson correlation coefficients and visualized the results in a correlation matrix (Figure 1B). All correlations were above 0.7 (Figure 1B). To assess the similarity between the SZ and control groups, we calculated the Pearson correlation coefficient of the protein intensity means calculated for each group. This correlation was 0.989 , indicating that globally the cerebellar proteomes of SZ and control individuals were highly similar (data not shown). Unsupervised hierarchical clustering analysis of the proteomic profiles was able to segregate controls and SZ samples, with the exception of five controls (\#8, \#7, $\# 4, \# 12$ and \#14) (Figure 1C). We further investigated whether the demographic- and tissuerelated features could explain the differential clustering of these controls and observed that although four of these controls segregated together, none of the variables influence this segregation (Figure S1). We identified 250 proteins significantly regulated (16.9\%) in SZ with an FDR of $<0.1$ (Supplementary Dataset S2) (142 proteins down-regulated and 108 up-regulated). None of the regulated proteins showed significant correlation with PMD, $\mathrm{pH}$ or chlorpromazine dose (FDR < 0.1) (Supplementary Datasets S3-S5) for any altered protein. A volcano plot was used to categorize proteins as up or down-regulated based on the fold change $\left(\log _{2}\right.$ FC) between SZ and control cases and the corrected $p$-value $\left(-\log _{10}\right.$ (q-value) adjusted to FDR < 0.1). Most of the significant changes were displayed between 0.2 and $0.6 \log 2$ FC (Figure 1 D). We found that only 56 of the 250 altered proteins had been previously reported in a gene expression study in an iPSC model of SZ [28], and that only 16 altered proteins had been reported in a microarray assay in human cerebellum [25] (Figure 1E, Supplementary Dataset S2). Eighty-six altered proteins in the cerebellum had been previously reported as altered in other brain regions in SZ, and 20 proteins had been reported in two recent cerebellar proteomic studies [26,27] using different designs (sample pooling versus individual sample analyses), labelling of peptides (chemical labelling quantification versus label-free quantification), type of lysates (cellular fractioning versus whole extracts), mass spectrometry instruments (LTQ-Orbitrap XL, Thermofisher or DS-11, DeNovix versus Q-Exactive, Thermofisher) and age of SZ subjects, among others (Table S2 and Supplementary Dataset S2). 


\subsection{Gene Ontology Enrichment Analysis}

Of the 108 up-regulated proteins, those related to stress were found to be the most enriched in the disease category analysis, comprising $12 \%$ of the total altered proteins (Figure 2A and Table 1). The up-regulated group was enriched in proteins related to structural and signaling biological functions (Figure 2B and Table 1 ) and to six pathways: vesicle-mediated transport, apoptosis, Rho GTPase effectors, signaling by Rho GTPases, axon guidance and the cell cycle (Figure 2C). Half of the altered proteins in the stress category (SOD1, MYH9, PDIA3, MAPK1, RPS3, YWHAE and YWHAZ) were also found in the group of proteins found to be enriched in a number of biological processes and pathways mainly related to axonal development and functioning (Table 1). Furthermore, our analysis showed that COMT is a protein that was only found in the stress category. COMT was not involved in other enriched categories in the cerebellum.

Of the 142 down-regulated proteins, those involved in mitochondrial diseases were found to be the most enriched in the disease category analysis, also comprising $12 \%$ of the total altered proteins (Figure 2A and Table 1). Analysis of the biological processes of the down-regulated proteins revealed significant enrichment of terms related to energy metabolism (Figure 2B and Table 1), and two predominant pathways were found to be enriched: the citric acid (TCA) cycle/respiratory electron transport and neutrophil degranulation (Figure 2C). Most of the altered proteins in the mitochondrial disease category (DLD, SLC25A4, NDUFA4, NDUFB5, NDUFB6, NDUFB9, NDUFS1, NDUFA12, UQCRB, CAPN1 and SL25A12) were also found in the group of proteins found to be enriched in energy-related functions (Table 1). CAPN1 was also found in the group of proteins enriched in the neutrophil degranulation pathway category (Table 1).

For the subsequent analyses, the altered proteins also reported in gene expression and proteomic analyses in the cerebellum and in iPSC model for schizophrenia at mRNA level were used (see Supplementary Dataset S2 and Figure 1E). We thus investigated the overlap between the altered proteins of the enriched categories and the previously reported changes in these gene expression and proteomic studies. These analyses revealed that 38 and 8 non-redundant altered proteins of the enriched categories in our proteomic study were previously reported in transcriptomic and proteomic reports, respectively (Table 1). 
Table 1. Non-redundant categories of disease, gene ontology and pathways among 250 altered proteins filtered by multiple comparison, FDR = 0.1 .

\begin{tabular}{|c|c|c|c|c|c|c|c|}
\hline CLASSIFICATION & CATEGORY & PROTEIN OVERLAP IN CATEGORY & Total Number & Observed Number & $\mathbf{E}$ & $p$-Value & FDR \\
\hline & & Up-regula & d proteins & & & & \\
\hline \multirow{3}{*}{ DISEASES } & Stress & $\begin{array}{c}\text { SYCRIP; COMT; TXN2; PDIA3 }{ }^{\mathrm{b}} \text {; HSPA9; } \text { MYH9 }^{\mathrm{a}} \text {; } \\
\text { NACA }^{\text {b }} \text { MAPK1; RPS3; SOD1 }^{\mathrm{b}} \text { MWHAE }^{\mathrm{b}} \text {; } \\
\text { YWHAZ; USP7 }^{\mathrm{b}}\end{array}$ & 592 & 13 & 2.20 & $2.30 \times 10^{-7}$ & $6.02 \times 10^{-4}$ \\
\hline & Drug interaction with drug & 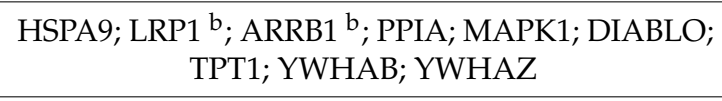 & 423 & 9 & 1.57 & $2.56 \times 10^{-5}$ & $3.36 \times 10^{-2}$ \\
\hline & $\begin{array}{l}\text { Neurodegenerative } \\
\text { diseases }\end{array}$ & $\begin{array}{l}\text { DCTN1; HSPA9; LRP1 b; MAP1B; RTN1 b; SNCG; } \\
\text { SNRPD1; SOD1 b; UCHL1 }\end{array}$ & 473 & 9 & 1.76 & $6.11 \times 10^{-5}$ & $5.33 \times 10^{-2}$ \\
\hline \multirow{10}{*}{$\begin{array}{l}\text { BIOLOGICAL } \\
\text { PROCESSES }\end{array}$} & $\begin{array}{l}\text { Regulation of cytoskeleton } \\
\text { organization }\end{array}$ & $\begin{array}{c}\text { ARPC2 }^{\text {b }} \text {; ARPC1A }{ }^{\text {b }} \text {; DCTN1; CLASP1; } \\
\text { ARHGDIA; LRP1 }{ }^{\text {b }} \text { PAFAH1B1 a ; MAPK1; RPS3; } \\
\text { SPTAN1 }{ }^{\text {b }} \text {; PM1; CAPZA2 }\end{array}$ & 414 & 12 & 2.08 & $9.29 \times 10^{-7}$ & $7.08 \times 10^{-4}$ \\
\hline & Organelle localization & $\begin{array}{c}\text { DCTN2 b; DCTN1; CLASP1; MAP1B; MYH9 a } \\
\text { NUMA1 }{ }^{\text {b }} \text {; PAFAH1B1 }{ }^{\text {a }} \text {; UCHL1; YWHAZ; } \\
\text { CADPS; NAPA }{ }^{\text {a,b }} \text {, LIN7A }^{\text {b }}\end{array}$ & 495 & 12 & 2.49 & $5.91 \times 10^{-6}$ & $2.25 \times 10^{-3}$ \\
\hline & Axon development & $\begin{array}{c}\text { RAB10; RAB21 a ; ARHGDIA; MAP1B; NRCAM; } \\
\text { PAFAH1B1 a; PITPNA b; MAPK1; DPYSL5; } \\
\text { SPTAN1 b; UCHL1 }\end{array}$ & 452 & 11 & 2.27 & $1.46 \times 10^{-5}$ & $3.71 \times 10^{-5}$ \\
\hline & $\begin{array}{c}\text { Establishment or } \\
\text { maintenance of cell polarity }\end{array}$ & $\begin{array}{c}\text { RAB10; CLASP1; MAP1B; } \text { MYH9 }^{\mathrm{a}} \text {; NUMA1 }{ }^{\mathrm{b}} \\
\text { PAFAH1B1 } \\
\text { a } \text { LIN7A }^{\mathrm{b}}\end{array}$ & 168 & 7 & 0.85 & $2.10 \times 10^{-5}$ & $4.0 \times 10^{-3}$ \\
\hline & $\begin{array}{l}\text { Regulation of cell } \\
\text { morphogenesis }\end{array}$ & $\begin{array}{l}\text { ARPC } 2^{\text {b; }} \text { RAB21 }{ }^{\text {a; }} \text { ARHGDIA; MAP1B; MYH9 a } \\
\text { NRCAM; PAFAH1B1 }{ }^{\text {a }} \text {; C1QBP; TPM1; YWHAH }\end{array}$ & 433 & 10 & 2.18 & $5.78 \times 10^{-5}$ & $6.29 \times 10^{-3}$ \\
\hline & $\begin{array}{l}\text { Regulation of apoptotic } \\
\text { Signaling pathway }\end{array}$ & $\begin{array}{l}\text { PDIA3 }{ }^{\text {b; }} \text { HNRNPK; RPS3; SOD1 }{ }^{\text {b }} \text {; TPT1; } \\
\text { YWHAB; YWHAE }{ }^{\text {b }} \text {; YWHAH; YWHAZ }\end{array}$ & 369 & 9 & 1.86 & $9.24 \times 10^{-5}$ & $8.80 \times 10^{-3}$ \\
\hline & $\begin{array}{l}\text { Multicellular organismal } \\
\text { signaling }\end{array}$ & $\begin{array}{l}\text { NRCAM; ATP2B1; ATP2B3; PAFAH1B1 a ; SOD1 }{ }^{\text {b }} \text {; } \\
\text { YWHAE }{ }^{\mathrm{b}}\end{array}$ & 472 & 9 & 2.38 & $5.74 \times 10^{-3}$ & $3.36 \times 10^{-2}$ \\
\hline & $\begin{array}{l}\text { Regulation of anatomical } \\
\text { structure size }\end{array}$ & 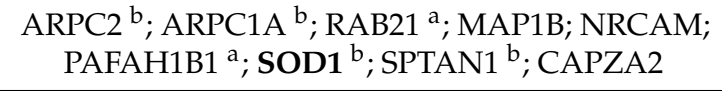 & 472 & 9 & 2.36 & $5.74 \times 10^{-4}$ & $3.36 \times 10^{-2}$ \\
\hline & Cytosolic transport & VPS26B; DCTN1; RAB21 a; SNX5 b; MAPK1 & 138 & 5 & 0.69 & $6.46 \times 10^{-4}$ & $3.51 \mathrm{v} 10^{-2}$ \\
\hline & $\begin{array}{c}\text { Microtubule- } \\
\text { basedmovement }\end{array}$ & $\begin{array}{l}\text { DCTN1; RAB21 a; MAP1B; PAFAH1B1 a; SOD1 }{ }^{\mathrm{b}} \text {; } \\
\text { UCHL1 }\end{array}$ & 226 & 6 & 1.14 & $9.50 \times 10^{-4}$ & $4.83 \times 10^{-2}$ \\
\hline
\end{tabular}


Table 1. Cont

\begin{tabular}{|c|c|c|c|c|c|c|c|}
\hline CLASSIFICATION & CATEGORY & PROTEIN OVERLAP IN CATEGORY & Total Number & Observed Number & $\mathrm{E}$ & $p$-Value & FDR \\
\hline & \multicolumn{7}{|c|}{ Up-regulated proteins } \\
\hline \multirow{7}{*}{ PATHWAYS } & Vesicle-mediated transport & 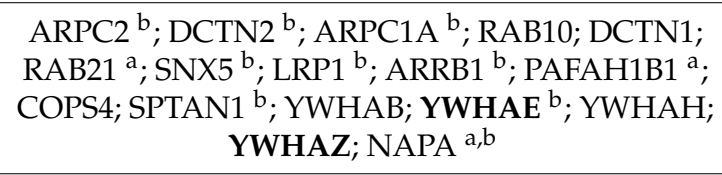 & 670 & 17 & 3.84 & $1.17 \times 10^{-7}$ & $1.87 \times 10^{-4}$ \\
\hline & Apoptosis & $\begin{array}{l}\text { PLEC; DIABLO; PSMB1; SPTAN1 b; YWHAB; } \\
\text { YWHAE }{ }^{\text {b } ; Y W H A H ; ~ Y W H A Z ~}\end{array}$ & 174 & 8 & 1 & $6.07 \times 10^{-3}$ & $1.57 \times 10^{-3}$ \\
\hline & Rho GTPase Effectors & $\begin{array}{c}\text { ARPC2 }^{\mathrm{b}} \text {; } \text { ARPC1A }^{\mathrm{b}} \text {; CLASP1; MYH9 }{ }^{\mathrm{a}} \text {; } \\
\text { PAFAH1B1 } \\
\text {; MAPK1; YWHAB; YWHAE }{ }^{\mathrm{b}} \text {; } \\
\text { YWHAH; YWHAZ }\end{array}$ & 311 & 10 & 1.78 & $9.32 \times 10^{-6}$ & $1.86 \times 10^{-3}$ \\
\hline & Signaling by Rho GTPases & $\begin{array}{c}\text { ARPC2 }^{\text {b; }} \text { ARPC1A }^{\text {b; }} \text { CLASP1; ARHGDIA; MYH9 } \\
\text { a; PAFAH1B1 }{ }^{\text {; }} \text { MAPK1; YWHAB; YWHAE }{ }^{\text {b }} \\
\text { YWHAH; YWHAZ }\end{array}$ & 446 & 11 & 2.56 & $3.82 \times 10^{-5}$ & $5.10 \times 10^{-3}$ \\
\hline & Axon guidance & 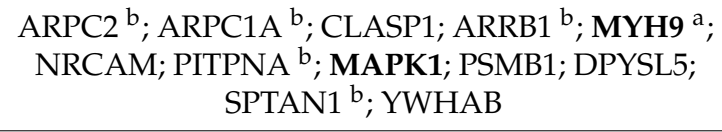 & 573 & 12 & 3.28 & $8.00 \times 10^{-5}$ & $8.00 \times 10^{-3}$ \\
\hline & Cell Cycle & $\begin{array}{c}\text { DCTN2 b; DCTN1; CLASP1; NUMA1 }{ }^{\text {b; }} \\
\text { PAFAH1B1 a ; MAPK1; PSMB1; YWHAB; YWHAE } \\
\text { b; YWHAH; YWHAZ }\end{array}$ & 635 & 11 & 3.64 & $8.40 \times 10^{-4}$ & $5.60 \times 10^{-2}$ \\
\hline & \multicolumn{7}{|c|}{ Down-regulated proteins } \\
\hline \multirow[t]{2}{*}{ DISEASES } & Mitochondrial diseases & $\begin{array}{c}\text { DLD; SLC25A4 }{ }^{\text {b }} \text {; SLC25A5; HSPD1; ACADVL }{ }^{\text {b }} \text {; } \\
\text { NDUFA4 }{ }^{\text {; }} \text { NDUFB5; NDUFB6; NDUFB9; } \\
\text { NDUFS1; NDUFA12 }{ }^{\text {; }} \text { SOD2; UQCRB; } \\
\text { SLC25A22; CAPN1; SLC25A12 }{ }^{\text {; }} \text {;DUFAF2 }\end{array}$ & 353 & 17 & 2.32 & $1.53 \times 10^{-10}$ & $4.0 \times 10^{-7}$ \\
\hline & Mental disorders & $\begin{array}{l}\text { ADH5; GABRA6 }{ }^{\text {b }} \text {; PCLO }{ }^{\text {b }} \text {; ANK3 } 3^{\text {b }} \text {; MARK1; } \\
\text { MOG; ATP1A3 }{ }^{\text {b }} \text { PIP4K2A }{ }^{\text {b }} \text {; SLC17A7; PTPRD } \\
\text { ( }\end{array}$ & 679 & 15 & 4.45 & $3.83 \times 10^{-5}$ & $2.01 \times 10^{-2}$ \\
\hline
\end{tabular}


Table 1. Cont.

\begin{tabular}{|c|c|c|c|c|c|c|c|}
\hline CLASSIFICATION & CATEGORY & PROTEIN OVERLAP IN CATEGORY & Total Number & Observed Number & $\mathrm{E}$ & $p$-Value & FDR \\
\hline & & Down-regul & ted proteins & & & & \\
\hline \multirow{4}{*}{$\begin{array}{l}\text { BIOLOGICAL } \\
\text { PROCESSES }\end{array}$} & $\begin{array}{l}\text { Generation of precursor } \\
\text { metabolites and energy }\end{array}$ & 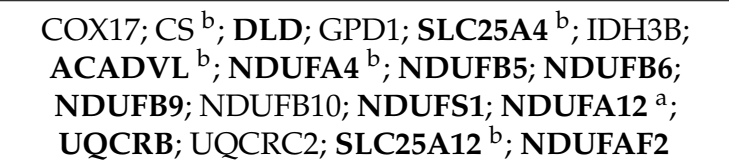 & 365 & 18 & 3.36 & $6.47 \times 10^{-9}$ & $4.93 \times 10^{-6}$ \\
\hline & $\begin{array}{l}\text { Mitochondrial respiratory } \\
\text { chain complex assembly }\end{array}$ & $\begin{array}{l}\text { COX17; NDUFB5; NDUFB6; NDUFB9; NDUFB10; } \\
\text { NDUFS1; NDUFA12 a; UQCRB; NDUFA2 }\end{array}$ & 290 & 11 & 2.67 & $7.61 \times 10^{-5}$ & $9.67 \times 10^{-3}$ \\
\hline & $\begin{array}{l}\text { Glycosyl compound } \\
\text { metabolic process }\end{array}$ & 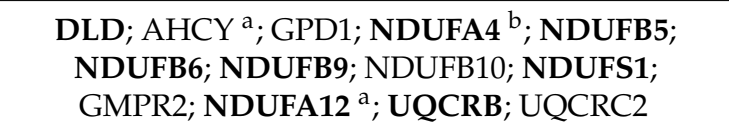 & 34 & 4 & 3.13 & $2.59 \times 10^{-4}$ & $2.45 \times 10^{-2}$ \\
\hline & $\begin{array}{l}\text { ATP hydrolysis-coupled } \\
\text { transmembrane transport }\end{array}$ & ATP1A1 ${ }^{\text {b }}$ ATP1A3 ${ }^{\text {b }}$ ATP6V1C1; ATP6AP1 ${ }^{\text {b }}$ & 37 & 4 & 0.34 & $3.59 \times 10^{-4}$ & $3.04 \times 10^{-2}$ \\
\hline \multirow[t]{2}{*}{ PATHWAYS } & $\begin{array}{l}\text { The citric acid (TCA) cycle } \\
\text { and respiratory electron } \\
\text { transport }\end{array}$ & $\begin{array}{l}\text { CS }^{\text {b }} \text {; DLD; IDH3B; NDUFA4 }{ }^{\text {b }} \text {; NDUFB5; } \\
\text { NDUFB6; NDUFB9; NDUFB10; NDUFS1; } \\
\text { NDUFA12 }{ }^{\text {; }} \text {; UQCRB; UQCRC2; NDUFAF2 }\end{array}$ & 171 & 13 & 1.79 & $2.19 \times 10^{-8}$ & $3.50 \times 10^{-5}$ \\
\hline & Neutrophil degranulation & $\begin{array}{l}\text { HUWE1; ARPC5; ACTR2; ATG7; SIRPA }{ }^{\text {b }} \text {; ERP44 } \\
\text { a,b; METTL7A }{ }^{\text {b }} \text {; DBNL; RAB37 }{ }^{\text {b }} \text {; ACLY } \text {; PRCP }^{\text {b }} \text {; } \\
\text { PSAP; RAP1B; CAPN1; GGH; CD47 }\end{array}$ & 487 & 16 & 5.07 & $4.0 \times 10^{-5}$ & $1.28 \times 10^{-2}$ \\
\hline
\end{tabular}

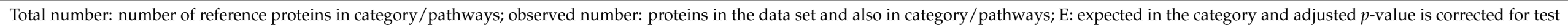

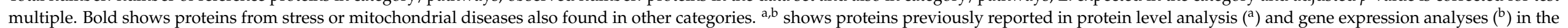
cerebellum (Supplementary Dataset S2). 
A

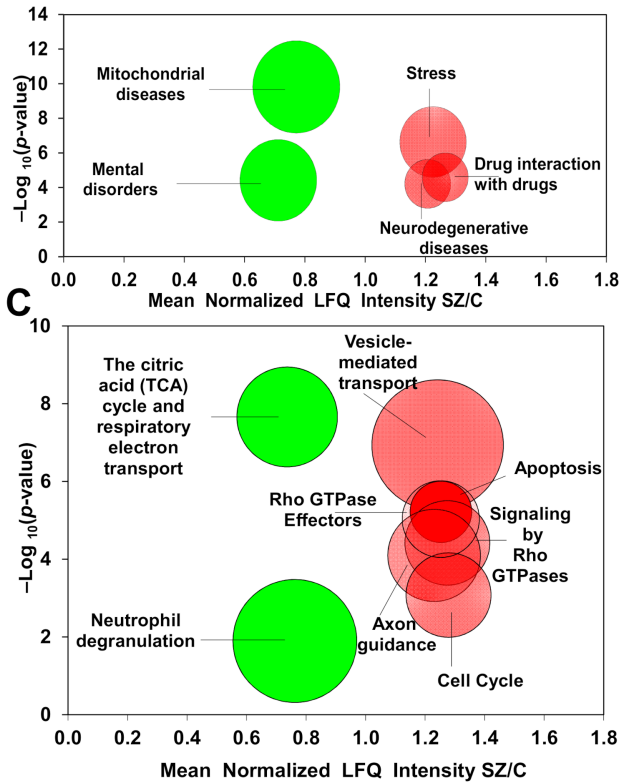

B

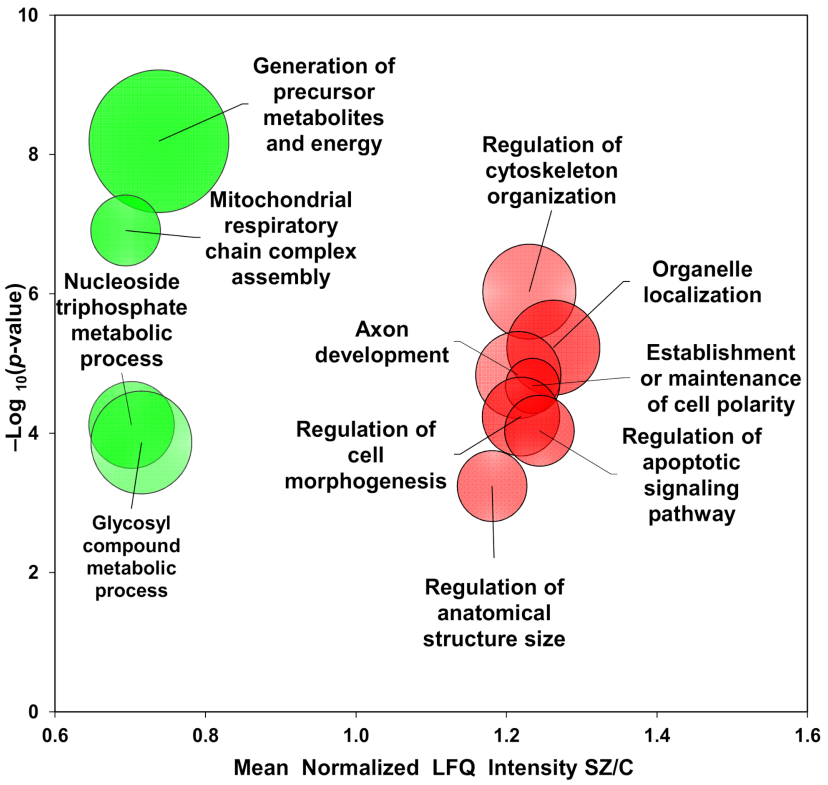

Figure 2. Enrichment analyses from proteome cerebellum in chronic schizophrenia. The bubble chart showing enriched disease categories (A), biological processes (B) and pathways (C) for 142 down-regulated proteins and 108 up-regulated proteins in SZ. (A) The enriched categories for the down-regulated proteins were mitochondrial diseases (PA447172) and mental disorders (PA447208), and for the up-regulated proteins they were stress (PA445752), drug interactions with drugs (PA165108622) and neurodegenerative diseases (PA446858). (B) Non-redundant enriched biological process categories for down-regulated proteins in SZ were generation of precursor metabolites and energy (GO: 0006091), mitochondrial respiratory chain complex assembly (GO: 0033108), nucleoside triphosphate metabolic process (GO: 0009141) and glycosyl compound metabolic process (GO: 1901657). For up-regulated proteins, the enriched biological functions were regulation of cytoskeleton organization (GO: 0051493), organelle localization (GO: 0051640), axon development (GO: 0061564), establishment or maintenance of cell polarity (GO: 0007163), regulation of cell morphogenesis (GO: 0022604), regulation of apoptotic signaling pathway (GO: 2001233), regulation of anatomical structure size (GO: 0090066) and microtubule-based movement (GO: 0007018). (C) The enriched pathway categories in SZ for the down-regulated proteins were citric acid (TCA) cycle/respiratory electron transport (R-HSA-1428517) and neutrophil degranulation (R-HSA-6798695). The enriched pathways for the up-regulated proteins were vesicle-mediated transport (R-HSA-5653656), apoptosis (R-HSA-109581), signaling mediated by Rho GTPase effectors (R-HSA-195258), signaling by Rho GTPases (R-HSA-194315), axon guidance (R-HSA-422475) and cell cycle (R-HSA-1640170). The X-axes show the mean of normalized LFQ intensity in SZ relative to control group for all the proteins that belonged to each category. The Y-axes show the $-\log _{10}$ enrichment $p$-value. The bubble size is directly proportional to the number of proteins represented in each enriched category of diseases, biological processes or pathways. Red color represents up-regulated proteins. Green color represents down-regulated proteins. SZ, schizophrenia; C, control.

\subsection{Network Generation from Enriched Pathways in the Cerebellum}

For the enriched up-regulated pathways, the network analysis showed overlapping pathways that were mainly related to axonal development and functioning (Figure 3A). The vesicle-mediated transport pathway showed the highest overlap with other pathways, with $52 \%$ overlapping with signaling by Rho GTPases proteins, 35\% with the cell cycle, 29\% with apoptosis and 23\% with axon guidance proteins (Figure 3A). Stress-related altered proteins in this network (MYH9, MAPK1, YWHAE and YWHAZ) belonged to at least three groups of proteins enriched in pathways and showed five to nine interactions with other altered proteins of the network (Figure 3A). Further, 14 proteins from the mixed module have been previously reported in proteomic and gene expression analyses (Figure 3A). 
Network analysis of enriched pathways for the down-regulated proteins revealed two distinct modules, one related to energy metabolism and the other consisting of neutrophil degranulation pathways (Figure 3B). The neutrophil degranulation proteins overlapped with secretory granular and secretory lumen pathways. Many mitochondrial diseaserelated altered proteins also formed part of the energy network (DLD, NDUFA4, NDUFB5, NDUFB6, NDUFB9, NDUFS1, NDUFA12 and UQCRB) and belong to respiratory electron transport with the exception of DLD, which belongs to the TCA cycle (Figure 3B). Moreover, nine proteins from the down-regulated network have been previously reported in proteomic and gene expression analyses (Figure 3B).

We used publicly available immunocytochemistry data to assess the expression of proteins of the up-regulated and down-regulated networks in the different layers of the cerebellum. In the up-regulated mixed module, most of the proteins were expressed at medium to high levels in all cerebellar layers with the exception of ARRB1 and SNX5 from axon guidance, which were only expressed in Purkinje neurons (Figure 3A). No information was available for the stress-related protein MYH9. In the down-regulated energy module, we found that all the proteins were widely distributed throughout the cerebellar layers (Figure 3B). For the neutrophil degranulation module, half of the proteins were expressed in all cerebellar layers, while the rest were expressed in two layers with the exception of ATG7, which was only expressed in Purkinje cells, and CD47, which was only expressed in the granular layer (Figure 3B).
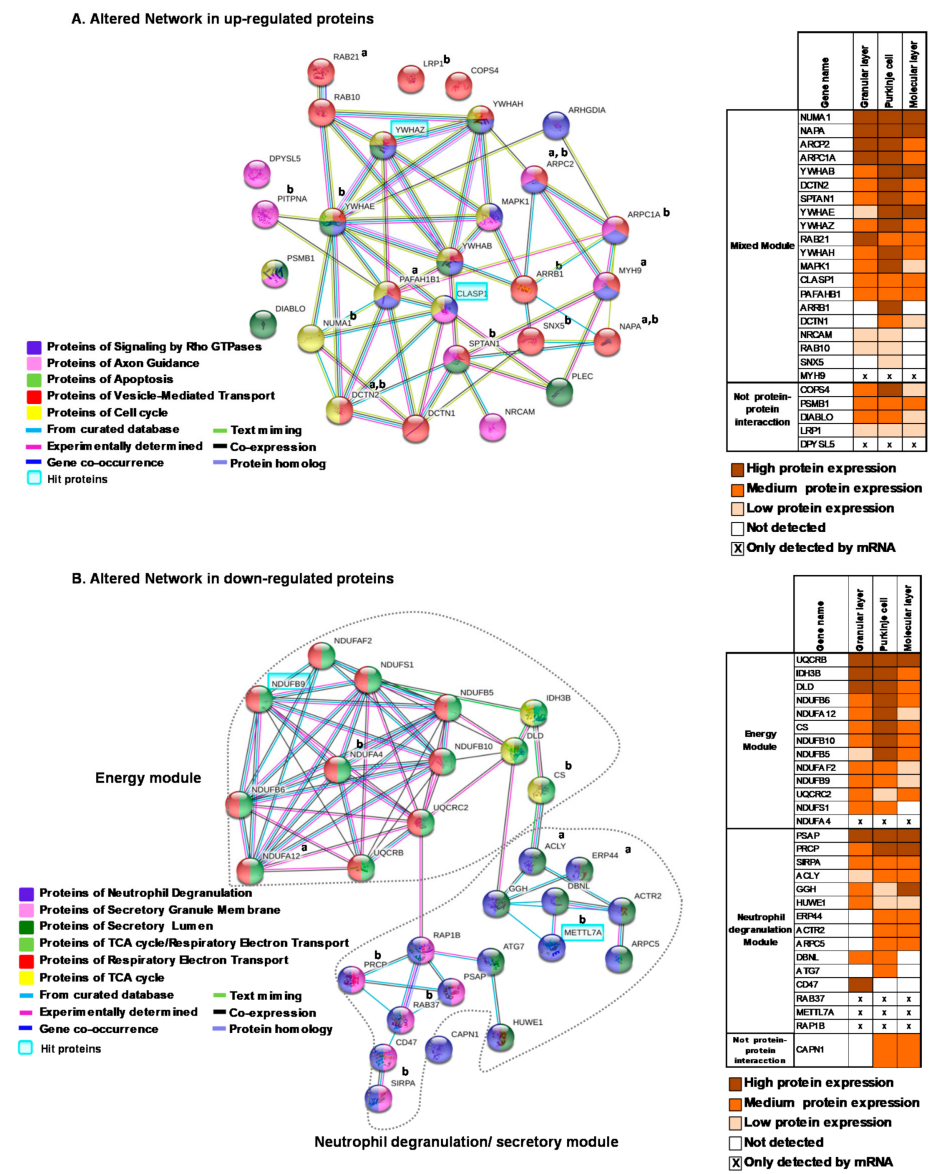

Figure 3. Network generation formed by altered pathways in cerebellum. (A) A protein-protein interaction network for up-regulated pathways. (B) A protein-protein interaction network for down-regulated pathways. The interaction overview shows how proteins overlap in the different enriched pathways (Figure 2C). Each node represents a protein. Color denotes membership to the module. The colored edge (connections between nodes) represents the type of interaction between 
nodes. Highlighted gene symbols represent the most robust hit protein for each module. In the mixed module, the candidate selected belonged to at least three different pathways. ${ }^{\text {a }}$ indicates the proteins previously report in the proteomic studies in cerebellum; ${ }^{b}$ indicates proteins previously reported in the gene expression analysis in iPSC and cerebellum. The right panels show the level of protein expression determined by immunohistochemistry for each protein in the modules and their localization in the different layers in the cerebellum.

\subsection{Analysis of Altered Robust Candidates in Double-Hit Stress Murine Models}

For each network module, we identified one or two robust protein candidates for further investigation of the influence of early postnatal stress based on the detected LFQ-intensity fold change and coefficient of variation $(<0.35)$ (Figure 4; Supplementary Dataset S6). The selected proteins were YWHAZ (vesicle-mediated transport and stressrelated protein) and CLASP1 (axonal guidance) for the mixed module, NDUFB9 for the energy module and METTL7A for the neutrophil degranulation module (Figure 4; Supplementary Dataset S6). METTL7A was also found altered in previous gene expression studies (Table 1).

Two independent double-hit murine stress models were used. The models were maternal deprivation combined with an additional stressor: social isolation (MD/Iso) or chronic restraint stress (MD/RS). Altered behavior was confirmed in these models (Supplementary Materials and Figure S2). CLASP1 was down-regulated in the MD/Iso model but up-regulated in the SZ cohort (Figure 4A and Figure S3A). No significant changes were found in the DM/RS model for CLASP1 (Figure 4A). YWHAZ, which was up-regulated in the SZ cohort and previously related to stress, did not show any change in either of the two SZ murine models (Figure 4B and Figure S3B). We observed that NDUFB9 levels were reduced in the human SZ cohort and in the MD/Iso model but not in the MD/RS model (Figure 4C and Figure S3C). METTL7A showed a decrease in protein expression levels in the chronic SZ cohort and in both murine models (Figure $4 \mathrm{D}$ and Figure S3D).
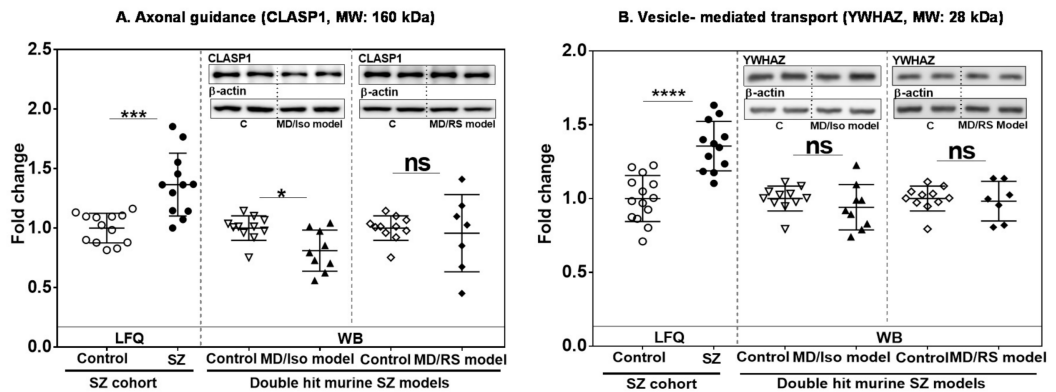

C. TCA-Respiratory electron transport (NDUFB9, MW: 22 kDa)

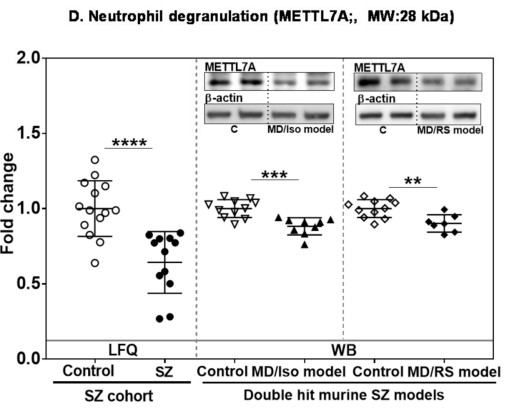

Figure 4. Analysis of hit proteins from altered pathways in a human SZ cohort and two double-hit SZ murine models. Protein levels of candidate hit proteins CLASP1 (A), YWHAZ (B), NDUFB9 (C) and METTL7A (D) from the indicated enriched pathway in SZ were analyzed in the cerebellum of the human SZ cohort (control: $n=14$; SZ =12) by proteomics, and in the two double-hit SZ murine 
models, maternal deprivation combined with social isolation (MD/Iso) or chronic restraint stress (MD/RS) (control: $n=11$; MD/Iso model: $n=9$; MD/RS model: $n=8$ ) by immunoblot. TCA-RET: citric acid cycle-respiratory electron transport. VTM: vesicle-mediated transport. SZ, schizophrenia. LFQ, Label free quantitative. WB, Western blot. Full images of immunoblots are available in Figure S3. Statistical analysis was performed using Student's $t$-test for samples with normal distribution, and the Mann-Whitney U test was carried out for non-parametric distribution in the MD/RS model for NDUFB9 and the MD/Iso and MD/RS models for CLASP1 and YWHAZ. Protein levels were normalized to the mean of the controls. Individual values represent the protein levels for each subject or animal. Means and standard deviations are shown in the graphs. ns: not significant, ${ }^{*} p<0.05$, ** $p<0.01,{ }^{* * *} p<0.001,{ }^{* * * *} p<0.0001$.

\section{Discussion}

Our study characterized the proteomic alterations for the cerebellar cortex in chronic schizophrenia. To the best of our knowledge, this is the first time in which the individual proteomic signature allows most SZ cases to be segregated from healthy controls in unsupervised analysis, similarly as that achieved in some gene expression studies [25,29].

\subsection{Up-Regulated Proteins Related to Stress and Axonal Functions}

A subset of the up-regulated proteins has been previously related to stress diseases. In this context, psychosocial stress has been shown to be mediated by cortisol, resulting in decreased blood flow in the cerebellum, and to be associated with the altered resting state of this area $[19,23]$. Other types of stress have also recently been found to alter the connectivity of the cerebellum with the hippocampus and its reactivity to cortisol [20,22]. A number of the proteins in the stress category (MYH9, MAPK1, YWHAE and YWHAZ) also form part of the highly interacting proteins of the network comprised of proteins with multiple roles in vesicle-mediated transport, axon guidance, cell cycle and/or signaling by Rho GTPases. In addition, one member of this upregulated network, CLASP1 from axonal guidance, was found to be regulated by stress in one murine model (see discussion of the role in Section 3.1.2). This protein also forms multiple interactions with other partners of the network, suggesting that maternal deprivation and social isolation could have a broader impact on axonal communication in the cerebellum. Together, this evidence suggests that an increase in proteins that have roles in multiple pathways and that are associated with stress conditions in the cerebellum could mediate the altered cerebellar functioning and its connectivity with other brain regions in schizophrenia. In addition, our analyses identify that catechol O-methyltransferase enzyme (COMT) was only found in the stress disease category. COMT participates in the metabolism of catecholamines such as dopamine and has been associated as a risk gene for SZ [30]. In the context of stress, studies have shown that the genetic variants of COMT could modulate the stress response, increasing or decreasing the release to blood of molecules involved in the stress response [31,32]. In $\mathrm{SZ}$, it has been reported the COMT genetic variant with higher activity on the dopamine degradation in the prefrontal cortex could be related to an impairment in the cognitive functions and working memory [33,34]. In the context of neurodevelopmental disorders, only one study associated an altered activity of COMT in the cerebellum to the impairment of executive function in attention-deficit/hyperactivity disorder [35]. However, we have not found functional studies of COMT in the cerebellum in SZ. Thus, in the context of SZ, altered COMT levels found in the cerebellum could lead to altered stress response and dopaminergic metabolism dysfunction. These findings also support the susceptibility of this brain area to psychosocial stress in schizophrenia.

\subsubsection{Vesicle-Mediated Transport}

In our proteomic study, we found up-regulated pathways related to vesicle-mediated transport. In neurons, altered transport could limit effectiveness in neuronal communication [36]. Defective synaptic transmission and neurotransmitter release [37] decreases in pre-synaptic vesicle proteins [38,39], and altered levels of proteins involved in synaptic 
vesicle fusion $[40,41]$ have been associated with SZ. However, in our study we found an increase of this pathway that could be indicative of a compensatory strategy. YWHAZ was found to be up-regulated in our proteomic study and to form part of the group of proteins related to stress. However, we did not observe any significant changes in YWHAZ in these early postnatal stress-based models, suggesting that later stress in adolescence or adult life could be responsible for the altered levels detected in postmortem cerebellum in schizophrenia. Supporting our results, other proteomics studies in different brain regions of SZ subjects have shown altered levels of YWHAZ [42,43]. YWHAZ has a role as an adaptor protein of extracellular vesicles (EVs), which involves the stabilization of vesicles and synapsis [44]. The overexpression of YWHAZ found in our study could increase the formation and release of EVs carrying protein or miRNA to the synapsis, which could be a compensatory mechanism for defective synaptic activity in this disorder in the cerebellum (see Section 3.2).

\subsubsection{Axon Guidance}

Our proteomic study showed an altered axon guidance pathway in the cerebellum. Defects in neuronal connectivity during development have been proposed as an important cause of the etiopathology of SZ [45,46]. A study based on the SZ-GWAS database found the axon guidance pathway to be altered in this disorder [47]. CLASP1 was a protein from axon guidance down-regulated in schizophrenia and further studied in two murine stress models in this study. Our results showed decreased expression of CLASP1 in the maternal deprivation and social isolation murine models, showing that this combination of early postnatal stress leads to the down-regulation of this protein in the cerebellum. However, the addition to chronic restraint postnatal stress was not sufficient for altering CLASP1 levels. Our proteomic study in SZ subjects showed an up-regulation. This protein participates in neurite outgrowth by binding at microtubules [48]. One possible explanation for the up-regulation of CLASP1 in chronic schizophrenia could be the accumulation of this protein in the neuritic growth cone due to a decrease in energy production required for the assembly of CLASP1 at microtubules.

\subsection{Down-Regulated Proteins Related to Mitochondrial Disease, Energy Functions and Immune Response}

The down-regulated proteins were enriched in proteins with an implication in mitochondrial diseases. Most of the proteins of this category were also found in the group of proteins related to oxidative phosphorylation and TCA in this study. In SZ, altered mitochondrial function has been previously reported [49]. Furthermore, our network analyses showed two modules for the down-regulated network, namely energy metabolism and neutrophil degranulation.

\subsubsection{Energy Metabolism Module}

We found a down-regulation of proteins involved in the energy production in the cerebellum in schizophrenia. The cerebellum represents $11 \%$ of human brain weight [50], and the distribution of the energy it uses varies between different cell types. The more energy-demanding functions in Purkinje cells include the production of action potentials and maintenance of postsynaptic receptors, while granule cells consume more energy to propagate action potentials and support the resting potential [51]. In the context of SZ, studies of cerebellar activity showed decreased blood flow in this area during several tasks, including attention, social cognition, emotion and memory [52,53]. Other studies have also reported reduced cerebellar activity and altered connectivity linked to different stresses $[19,20,22,23]$, suggesting that the reduced cerebellar activity observed in schizophrenia could be influenced by stress life events.

Evidence of mitochondrial dysfunction in SZ includes genetic [54], metabolic [55] and enzymatic dysfunctions [56]; anatomical abnormalities [57]; and disturbed levels of proteins of glycolysis, TCA cycle, mitochondrial function and oxidative stress [58-61]. 
These studies are in line with our results showing a down-regulation of the energy network built by TCA cycle/respiratory electron transport and several mitochondrial proteins.

In our study, NDUFB9, the most robust candidate of the energy network involved in respiratory electron transport, was reduced in schizophrenia. It was also observed to be down-regulated in the double-hit postnatal stress murine model that combined maternal deprivation with social isolation but not in combination with chronic restraint stress, suggesting that the down-regulation of respiratory electron chain proteins altered in schizophrenia could be a social stress-induced response.

NDUFB9 is one of the multiple energy proteins that we found widely expressed in the cerebellum with moderate expression in the cerebellar granule layer and Purkinje layer. This protein is involved in the assembly of Complex I. Together with the activity of Complex I, NDUFB9 has been investigated in other brain areas in SZ [62,63]. Thus, the altered expression of NDUFB9 observed in this study could contribute to reducing energy metabolism in cerebellar cells through the disruption of Complex I in respiratory electron transport and could consequently decrease the propagation action potentials among the major neuron cell types of the cerebellar cortex in chronic SZ. Our study suggests that this mechanism could be induced by early postnatal social stress.

\subsubsection{Neutrophil Degranulation Module}

Our study observed down-regulation of several proteins involved in the various processes of the neutrophil degranulation pathway in cerebellar tissue. Neutrophil degranulation is one of the first defense barriers against infection [64]. An imbalance of the immune system is one of the hypotheses underlying SZ [65]. In our study, METTL7A was observed to be consistently down-regulated in both SZ human samples and in both combinations of early postnatal stress murine models, suggesting that altered METTL7A in chronic schizophrenia could be an early event that is induced by different types of combinations of postnatal stress, and that other members of this network could also be influenced by stress. Further studies are needed to investigate this latter possibility.

METTL7A, a member of the METTL family of methyltransferases, is of interest as it has been poorly studied; indeed, only one study investigated its role in RhoBTB1 signaling in maintaining Golgi integrity [66], a function that could be involved in neutrophil degranulation. In the context of neutrophil degranulation, the altered expression of METTL7A could impair Golgi integrity and contribute to the abnormal formation of secretory granules in neutrophils, altering the first defense barrier of the innate immune response in chronic SZ. Limited information is available about METTL7A deregulation in the context of schizophrenia. In line with our results, previous studies have reported a decrease in the RNA and protein levels on the prefrontal cortex (Brodmann area 46/10) and the anterior cingulate cortex (Brodmann area 24) in SZ subjects, respectively [67,68]. Reduced mRNA levels of METTL7A have also been found in the induced pluripotent stem cells (iPSC) model for schizophrenia [28]. However, another study on the prefrontal cortex (Brodmann area 9) reported an increase in the RNA levels of METTL7A [69]. Thus, METTL7A is a putative relevant candidate altered in different biological substrates in the context of schizophrenia that has been found reduced in the cerebellum in this disorder and modulated by stress in our study. Further studies are needed to understand the role of the reduction of METTL7A in the cerebellum in the context of SZ.

The use of the human postmortem brain constitutes a valuable tool to understand the molecular pathways altered in several psychiatric disorders. However, it has limitations. Firstly, confounding factors such as age, postmortem delay and $\mathrm{pH}$ must be carefully explored. In our proteomic study, we did not find any association between these variables and the significantly altered proteins in the cerebellum. Secondly, patients with chronic schizophrenia had long-term and heterogeneous antipsychotics medications. Some candidates from the upregulated proteins are involved in drug to drug interactions, which suggest a possible effect of antipsychotic medications on our findings. Although, no associations were found with a chlorpromazine equivalent dose and altered proteins, the 
effect of antipsychotic could not be completely rule out. Thirdly, our study only included men, who do not represent a real population of this disorder. Fourthly, our study consisted entirely of elderly individuals due to the type of sample available.

\section{Methods and Materials}

\subsection{Postmortem Human Brain Tissue}

Samples from the cerebella of subjects with chronic schizophrenia $(n=12)$ and healthy controls $(n=14)$ were obtained from the neurologic tissue collection of the Parc Sanitari Sant Joan de Déu Brain Bank (Barcelona, Spain) (30) and the Institute of Neuropathology of the Universitari de Bellvitge Hospital (Barcelona, Spain), respectively. We matched SZ and control groups by gender (only male patients were included), age, postmortem delay (PMD) and $\mathrm{pH}$ (Table S1). The last daily chlorpromazine equivalent dose for the antipsychotic treatment of patients was calculated based on the electronic records of the last drug prescriptions administered up to death, as described previously [70]. Human cerebellar lateral cortex was dissected from coronal slabs stored at $-80^{\circ} \mathrm{C}$, extending from the pial surface to white matter only including grey matter. See Supplementary Methods for more details.

\subsection{Label Free Quantification Proteomic Analysis Mass Spectrometry}

Protein extracts were prepared as described previously [71]. Protein concentration was determined by Bradford assay (Bio-Rad, Hercules, CA, USA). Proteomic samples were prepared as described in the Supplementary Methods, using a starting protein amount of $200 \mu$ g. Peptide mixtures were analyzed by single-shot liquid chromatography-tandem mass spectrometry (LC-MS/MS) in a Q-Exactive mass spectrometer (Thermofisher Scientific, Waltham, MA, USA) using a top 20 data-dependent acquisition method. Mass spectrometry data were analyzed using MaxQuant. A target-decoy database search strategy was used to guide filtering and estimate false discovery rates (FDRs). Peptides matches were filtered to an FDR of $\leq 0.01$. The mass spectrometry proteomics data were deposited in the ProteomeXchange Consortium via the PRIDE repository with the dataset identifier PXD024937. The minimum required peptide length was seven residues. Label-free quantification (LFQ) was selected for individual protein comparisons between control and SZ groups. Proteins quantified in fewer than 7 samples per group were excluded from the analysis. The normalized LFQ intensity referred to the mean intensity of the controls. A significance value for each quantified protein was calculated using Student's $t$-test and adjusted for multiple-hypothesis testing using the Benjamini-Hochberg method [72] FDRs were computed for all significant values, and the FDR threshold was set to 0.1. The quantified proteins were imported into the Perseus software platform (version 1.6.1.3 http:/ / coxdocs.org/doku.php?id=perseus:start\#cite, accessed on 22 June 2021) for quality control and further analysis [73]. See Supplementary Methods for more details.

\subsection{Bioinformatic Analysis}

To visually identify significantly altered proteins, we plotted the $\log _{2}$ of the fold change of normalized LFQ intensities between schizophrenia and control samples along with the FDR adjusted $-\log _{10}$ (q-value). We used the Schizophrenia Database [74] and FunRich Tool v.3.1.3 [75] to compare the identified altered proteins to those previously reported in gene expression studies. To perform the disease, gene ontology (GO) and pathway analyses, we used the Webgestalt-mediated ORA method. Disease terms were obtained from the PharmacoGenetics Knowledge Base (PharmGKB) and Gene List Automatically Derived For You (GLAD4U) databases [76,77]. For the GO analysis, we performed a non-redundant enriched categories analysis. For the pathway analysis, we used the Reactome database, and for the network generation, we used String version 11.0 [78]. To perform the screening on protein localization analysis in different tissue layers in the cerebellum we used the Human Protein Atlas database [79]. The enrichment analyses were set to an FDR of 0.1. We selected 0.1 as a threshold for FDR to detect a broad panel of altered proteins and enriched 
gene ontology categories to provide a global overview and generate a broader picture of the altered networks.

\subsection{Stress Murine Models}

Three pregnant Wistar rats (Harlan Ibérica, Spain) at gestation day 15 were individually housed in a controlled setting. One of the litters was used as a control group and the other as a double-hit model randomly. After birth, at postnatal day (PD) 9, both litters were exposed to maternal deprivation for $24 \mathrm{~h}$. On PD21, the pups were weaned, and one of the litters was isolated for 5 weeks (PD21-56); the pups were housed individually and denied physical contact with their siblings. After isolation, the pups were regrouped (MD/Iso). The other litter was exposed to restraint stress between PD 72 and 78 for $6 \mathrm{~h}$ every day (MD/RS). These conditions represent well-suited murine models for the study of neuropsychiatric dysfunctions [80,81]. Group sample sizes were CT, $n=11$; MD/Iso, $n=9$; $\mathrm{MD} / \mathrm{RS}, n=7$. The animals were subjected to cervical dislocation. The brain was removed from the skull and the cerebellum was excised and frozen at $-80{ }^{\circ} \mathrm{C}$ until assayed. Samples were homogenized by sonication in PBS $(\mathrm{pH}=7)$ mixed with a protease inhibitor cocktail (Complete ${ }^{\circledR}$, Roche, Spain). After adjusting protein levels, homogenates of cerebellar tissue were mixed with loading buffer, and $15 \mu \mathrm{g}$ was loaded into an electrophoresis gel, then blotted onto a nitrocellulose membrane with a semi-dry transfer system (Bio-Rad) and incubated with specific antibodies against (1) methyltransferase-like 7A (METTL7A); (2) NADH dehydrogenase [ubiquinone] 1 beta subcomplex subunit 9 (NDUFB9); (3) CLIP-associating protein 1 (CLASP1); (4) 14-3-3 protein zeta/delta (YWHAZ); and (5) beta-actin ( $\beta$-actin). See Supplementary Maethods for more detailed information.

\subsection{Statistical Analysis}

Normal distribution of variables was determined using the D'Agostino-Pearson test. Demographics and tissue feature of the samples were compared between cases and controls using Student's $t$-test for parametric quantitative variables and the Mann-Whitney U test for non-parametric variables. Spearman or Pearson correlation analysis was carried out to detect association of our proteomic data with other clinical-, demographic- and tissuerelated variables (age, postmortem delay, $\mathrm{pH}$, daily chlorpromazine equivalent dose and duration of illness). For experiments with animal models, we performed outliers analysis using the ROUT method, unpaired Student $t$-tests for parametric variables and MannWhitney U tests for non-parametric variables. Statistical analysis was performed with Graph Prism version 7.00 (GraphPad Software, San Diego, CA, USA). The significance level was set to 0.05 .

\section{Conclusions}

Altogether, our study provides altered stress- and mitochondrial disease-related proteins involved in energy, immune and axonal networks in the cerebellum in schizophrenia, suggesting that the accumulation of altered events in these networks could lead to a failure in the normal cerebellar functions, impairing synaptic response and the defense mechanisms of this region against external harmful injuries in schizophrenia. Further double hit murine models point out that some of the molecular network alterations observed in schizophrenia could be induced by different combinations of stress exposure during the late postnatal developmental phase of the cerebellum. Thus, these results suggest that the cerebellum is an area vulnerable to accumulate molecular errors induced by stress during early postnatal life in schizophrenia. These findings could provide a panel of possible molecular targets and pathways related to stress and mitochondrial function to explore specific antipsychotic treatments in these murine stress models. These pre-clinical studies could be useful for the development of novel combinations of antipsychotics for schizophrenia in future clinical studies. 
Supplementary Materials: The following are available online at https://www.mdpi.com/article/10 .3390/ijms221810076/s1.

Author Contributions: Conceptualization, A.V.-M., J.V. and B.R.; data curation, R.R.-M.; formal analysis, A.V.-M., R.R.-M., K.S.M., B.G.-B., Á.G.B., J.R.C. and B.R.; funding acquisition, J.V. and B.R.; Investigation, A.V.-M., R.R.-M., K.S.M., B.G.-B., Á.G.B., J.R.C. and B.R.; methodology, A.V.-M., R.R.M., K.S.M., B.G.-B., Á.G.B. and J.R.C.; project administration, J.V. and B.R.; resources, R.R.-M., K.S.M., B.G.-B., J.V. and B.R.; software, A.V.-M. and R.R.-M.; supervision, B.R.; validation, K.S.M., B.G.-B., Á.G.B. and J.R.C.; writing-original draft, A.V.-M. and B.R.; writing-review and editing, A.V.-M., R.R.-M., K.S.M., B.G.-B., J.R.C., J.V. and B.R. All authors have read and agreed to the published version of the manuscript.

Funding: This research was funded by a Miguel Servet grant (MS16/00153-CP16/00153 to BR) financed and integrated into the National R + D + I and funded by the Instituto de Salud Carlos III (Spanish Ministry of Health)—General Branch Evaluation and Promotion of Health Research—and the European Regional Development Fund (ERDF). This work was also supported by CONICYTDoctorado Becas Chile 2015 (72160426 grant number to AV), the Institute de Salud Carlos III (Spanish Ministry of Health) (PI18/00213 to BR) and the Spanish Ministry of Economy, Industry and Competitiveness (MINECO-EU-FEDER)-SAF2016-75500R and CIBERSAM. The proteomics work was supported by NIH grants (R35GM119536 and R01NS098329 to JV). JRC is a Ramon y Cajal researcher (MINECO and FEDER).

Institutional Review Board Statement: The proteomic study from human postmortem cerebellum was approved by the Institutional Ethics Committee of Parc Sanitari Sant Joan de Déu (code PIC151-16 and date approval 24 November 2016). All experimental protocols used for animal studies adhered to the guidelines of the Animal Welfare Committee of the Complutense University in accordance with European legislation (D2010/63/UE).

Informed Consent Statement: An antemortem written informed consent was obtained from each subject involved in this study.

Data Availability Statement: The mass spectrometry proteomics data have been deposited in the ProteomeXchange Consortium via the PRIDE repository with the dataset identifier PXD024937.

Acknowledgments: The authors thank the donors and their families for the donation of their brains, the collaboration of the team of the Hospital Universitari de Bellvitge Brain Bank and the team of the Banc de Teixits Neurologics of Parc Sanitari Sant Joan de Déu for their help. We thank Èlia Vila and Beatriz Moreno for their technical support.

Conflicts of Interest: The authors declare no conflict of interest.

\begin{tabular}{ll}
\multicolumn{2}{l}{ Abbreviations } \\
SZ & Schizophrenia \\
LC-MS/MS & $\begin{array}{l}\text { Liquid chromatography-tandem mass spectrometry } \\
\text { LFQ }\end{array}$ \\
Label free quantitative \\
DSM-IV & Diagnostic and Statistical Manual of Mental Disorders \\
PMD & Postmortem delay \\
FDR & False discovery rate \\
GO & Gene ontology \\
GLAD4U & Gene List Automatically Derived for You \\
iPSC & induced pluripotent stem cells \\
EVs & Extracellular vesicles \\
TCA & The citric acid \\
PD & Postnatal day \\
MD/Iso & Maternal deprivation with isolation \\
MD/RS & Maternal deprivation with restraint stress \\
PharmGKB & PharmacoGenetics Knowledge Base \\
METTL7A & Methyltransferase-like 7A \\
NDUFB9 & NADH dehydrogenase [ubiquinone] 1 beta subcomplex subunit 9
\end{tabular}




$\begin{array}{ll}\text { CLASP1 } & \text { CLIP-associating protein 1 } \\ \text { YWHAZ } & \text { 14-3-3 protein zeta/delta } \\ \text { COMT } & \text { Catechol O-methyltransferase } \\ \text { WB } & \text { Western Blot }\end{array}$

\section{References}

1. Rosato, M.; Stringer, S.; Gebuis, T.; Paliukhovich, I.; Li, K.W.; Posthuma, D.; Sullivan, P.F.; Smit, A.B.; van Kesteren, R.E. Combined cellomics and proteomics analysis reveals shared neuronal morphology and molecular pathway phenotypes for multiple schizophrenia risk genes. Mol. Psychiatry 2021, 26, 784-799. [CrossRef] [PubMed]

2. McGrath, J.; Saha, S.; Chant, D.; Welham, J. Schizophrenia: A concise overview of incidence, prevalence, and mortality. Epidemiol Rev. 2008, 30, 67-76. [CrossRef] [PubMed]

3. Hilker, R.; Helenius, D.; Fagerlund, B.; Skytthe, A.; Christensen, K.; Werge, T.M.; Nordentoft, M.; Glenthøj, B. Heritability of Schizophrenia and Schizophrenia Spectrum Based on the Nationwide Danish Twin Register. Biol. Psychiatry 2018, 83, 492-498. [CrossRef]

4. Davis, J.; Eyre, H.; Jacka, F.N.; Dodd, S.; Dean, O.; McEwen, S.; Debnath, M.; McGrath, J.; Maes, M.; Amminger, G.P.; et al. A review of vulnerability and risks for schizophrenia: Beyond the two hit hypothesis. Neurosci. Biobehav. Rev. 2016, 65, 185-194. [CrossRef]

5. Fatemi, S.H.; Folsom, T.D. The neurodevelopmental hypothesis of Schizophrenia, revisited. Schizophr. Bull. 2009, 35, 528-548 [CrossRef]

6. Maynard, T.; Sikich, L.; Lieberman, J.A.; LaMantia, A.-S. Neural development, cell-cell signaling, and the "two-hit" hypothesis of schizophrenia. Schizophr. Bull. 2001, 27, 457-476. [CrossRef]

7. Weinberger, D.R. Implications of Normal Brain Development for the Pathogenesis of Schizophrenia. Arch. Gen. Psychiatry 1988, 45, 1055. [CrossRef]

8. Holtzman, C.; Trotman, H.; Goulding, S.; Ryan, A.; MacDonald, A.; Shapiro, D.; Brasfield, J.; Walker, E. Stress and neurodevelopmental processes in the emergence of psychosis. Neuroscience 2013, 249, 172-191. [CrossRef]

9. Martínez-Téllez, R.I.; Hernández-Torres, E.; Gamboa, C.; Flores, G. Prenatal stress alters spine density and dendritic length of nucleus accumbens and hippocampus neurons in rat offspring. Synapse 2009, 63, 794-804. [CrossRef]

10. Shalev, U.; Weiner, I. Gender-dependent differences in latent inhibition following prenatal stress and corticosterone administration. Behav. Brain Res. 2001, 126, 57-63. [CrossRef]

11. Lemaire, V.; Koehl, M.; Le Moal, M.; Abrous, D.N. Prenatal stress produces learning deficits associated with an inhibition of neurogenesis in the hippocampus. Proc. Natl. Acad. Sci. USA 2000, 97, 11032-11037. [CrossRef]

12. Son, G.H.; Geum, D.; Chung, S.; Kim, E.J.; Jo, J.-H.; Kim, C.-M.; Lee, K.H.; Kim, H.T.; Choi, S.; Lee, C.J.; et al. Maternal stress produces learning deficits associated with impairment of NMDA receptor-mediated synaptic plasticity. J. Neurosci. 2006, 26, 3309-3318. [CrossRef]

13. Weiss, I.C.; Pryce, C.R.; Jongen-Rêlo, A.L.; Nanz-Bahr, N.I.; Feldon, J. Effect of social isolation on stress-related behavioural and neuroendocrine state in the rat. Behav. Brain Res. 2004, 152, 279-295. [CrossRef]

14. Giovanoli, S.; Engler, H.; Engler, A.; Richetto, J.; Feldon, J.; A Riva, M.; Schedlowski, M.; Meyer, U. Preventive effects of minocycline in a neurodevelopmental two-hit model with relevance to schizophrenia. Transl. Psychiatry 2016, 6, e772. [CrossRef]

15. Monte, A.S.; Mello, B.S.F.; Borella, V.C.M.; da Silva Araujo, T.D.S.; Da Silva, F.E.R.; De Sousa, F.C.F.; De Oliveira, A.C.P.; Gama, C.S.; Seeman, M.V.; Vasconcelos, S.M.M.; et al. Two-hit model of schizophrenia induced by neonatal immune activation and peripubertal stress in rats: Study of sex differences and brain oxidative alterations. Behav. Brain Res 2017, 331, 30-37. [CrossRef]

16. Weinberger, D.R. On the plausibility of "the neurodevelopmental hypothesis" of schizophrenia. Neuropsychopharmacology 1996, 14, 1-11. [CrossRef]

17. Marco, E.M.; Llorente, R.; Gallardo, M.L.; Mela, V.; Llorente-Berzal, Á.; Prada, C.; Viveros, M.-P. The maternal deprivation animal model revisited. Neurosci. Biobehav. Rev. 2015, 51, 151-163. [CrossRef] [PubMed]

18. Moreno-Rius, J. The cerebellum under stress. Front. Neuroendocrinol 2019, 54, 100774. [CrossRef] [PubMed]

19. De Quervain, D.J.F.; Henke, K.; Aerni, A.; Treyer, V.; McGaugh, J.L.; Berthold, T.; Nitsch, R.M.; Buck, A.; Roozendaal, B.; Hock, C. Glucocorticoid-induced impairment of declarative memory retrieval is associated with reduced blood flow in the medial temporal lobe. Eur. J. Neurosci. 2003, 17, 1296-1302. [CrossRef]

20. Hare, S.M.; Chiappelli, J.; Savransky, A.; Adhikari, B.M.; Wisner, K.; Kvarta, M.; Goldwaser, E.; Du, X.; Chen, S.; Rowland, L.M.; et al. The Role of Hippocampal Functional Connectivity on Multisystem Subclinical Abnormalities in Schizophrenia. Psychosom. Med. 2020, 82, 623-630. [CrossRef]

21. van Leeuwen, J.M.; Vinkers, C.H.; Vink, M.; Kahn, R.S.; Joëls, M.; Hermans, E.J. Disrupted upregulation of salience network connectivity during acute stress in siblings of schizophrenia patients. Psychol. Med. 2021, 51, 1038-1048. [CrossRef] [PubMed]

22. Quidé, Y.; Girshkin, L.; Watkeys, O.J.; Carr, V.J.; Green, M.J. The relationship between cortisol reactivity and emotional brain function is differently moderated by childhood trauma, in bipolar disorder, schizophrenia and healthy individuals. Eur. Arch. Psychiatry Clin. Neurosci. 2020, 271, 1089-1109. [CrossRef] [PubMed] 
23. Yan, Y.-J.; Huang, J.; Lui, S.S.Y.; Cheung, E.F.C.; Madsen, K.H.; Chan, R.C.K. The effect of effort-reward imbalance on brain structure and resting-state functional connectivity in individuals with high levels of schizotypal traits. Cogn. Neuropsychiatry 2021, 26, 166-182. [CrossRef] [PubMed]

24. Altman, J. Postnatal development of the cerebellar cortex in the rat. II. Phases in the maturation of Purkinje cells and of the molecular layer. J. Comp. Neurol. 1972, 145, 399-463. [CrossRef] [PubMed]

25. Chen, C.; Cheng, L.; Grennan, K.; Pibiri, F.; Zhang, C.; A Badner, J.; Gershon, E.S.; Liu, C. Two gene co-expression modules differentiate psychotics and controls. Mol. Psychiatry 2013, 18, 1308-1314. [CrossRef]

26. Vidal-Domènech, F.; Riquelme, G.; Pinacho, R.; Rodriguez-Mias, R.; Vera, A.; Monje, A.; Ferrer, I.; Callado, L.F.; Meana, J.J.; Villén, J.; et al. Calcium-binding proteins are altered in the cerebellum in schizophrenia. PLoS ONE 2020, 15, e0230400. [CrossRef]

27. Reis-De-Oliveira, G.; Zuccoli, G.; Fioramonte, M.; Schimitt, A.; Falkai, P.; Almeida, V.; Martins-De-Souza, D. Digging deeper in the proteome of different regions from schizophrenia brains. J. Proteom. 2020, 223, 103814. [CrossRef]

28. Brennand, K.; Simone, A.; Jou, J.; Gelboin-Burkhart, C.; Tran, N.; Sangar, S.; Li, Y.; Mu, Y.; Chen, G.; Yu, D.; et al. Modelling schizophrenia using human induced pluripotent stem cells. Nature 2011, 473, 221-225. [CrossRef]

29. Ramaker, R.C.; Bowling, K.M.; Lasseigne, B.N.; Hagenauer, M.H.; Hardigan, A.A.; Davis, N.S.; Gertz, J.; Cartagena, P.M.; Walsh, D.M.; Vawter, M.P.; et al. Post-mortem molecular profiling of three psychiatric disorders. Genome Med. 2017, 9, 1-12. [CrossRef]

30. Owen, M.J.; Williams, N.M.; O’Donovan, M. The molecular genetics of schizophrenia: New findings promise new insights. Mol. Psychiatry 2004, 9, 14-27. [CrossRef]

31. Armbruster, D.; Mueller, A.; Strobel, A.; Lesch, K.-P.; Brocke, B.; Kirschbaum, C. Children under stress-COMT genotype and stressful life events predict cortisol increase in an acute social stress paradigm. Int. J. Neuropsychopharmacol. 2012, 15, 1229-1239. [CrossRef]

32. Walder, D.J.; Trotman, H.D.; Cubells, J.F.; Brasfield, J.; Tang, Y.-L.; Walker, E.F. Catechol-O-methyltransferase modulation of cortisol secretion in psychiatrically at-risk and healthy adolescents. Psychiatr. Genet. 2010, 20, 166. Available online: https:/ /journals.lww.com/psychgenetics/Fulltext/2010/08000/Catechol_O_methyltransferase_modulation_of.5.aspx (accessed on 22 June 2021). [CrossRef]

33. Heinzel, S.; Riemer, T.G.; Schulte, S.; Onken, J.; Heinz, A.; Rapp, M.A. Catechol-O-methyltransferase (COMT) genotype affects age-related changes in plasticity in working memory: A pilot study. Biomed. Res. Int. 2014, 2014, 1-7. [CrossRef]

34. Egan, M.F.; Goldberg, T.E.; Kolachana, B.S.; Callicott, J.H.; Mazzanti, C.M.; Straub, R.E.; Goldman, D.; Weinberger, D.R. Effect of COMT Val108/158 Met genotype on frontal lobe function and risk for schizophrenia. Proc. Natl. Acad. Sci. USA 2001, 98, 6917-6922. [CrossRef] [PubMed]

35. Mizuno, Y.; Jung, M.; Fujisawa, T.X.; Takiguchi, S.; Shimada, K.; Saito, D.N.; Kosaka, H.; Tomoda, A. Catechol-O-methyltransferase polymorphism is associated with the cortico-cerebellar functional connectivity of executive function in children with attentiondeficit/hyperactivity disorder. Sci. Rep. 2017, 7, 1-8.

36. Barlan, K.; Rossow, M.J.; Gelfand, V.I. The journey of the organelle: Teamwork and regulation in intracellular transport. Curr. Opin. Cell Biol. 2013, 25, 483-488. [CrossRef]

37. Maher, B.J.; LoTurco, J.J. Disrupted-in-schizophrenia (DISC1) functions presynaptically at glutamatergic synapses. PLoS ONE 2012, 7, e34053. [CrossRef] [PubMed]

38. Mirnics, K.; Middleton, F.; Marquez, A.; Lewis, D.; Levitt, P. Molecular Characterization of Schizophrenia Viewed by Microarray Analysis of Gene Expression in Prefrontal Cortex. Neuron 2000, 28, 53-67. Available online: https: //www.cell.com/neuron/fulltext/S08966273(00)000854?_returnURL=https\%3A\%2F\%2Flinkinghub.elsevier.com\%2Fretrieve\% 2Fpii\%2FS0896627300000854\%3Fshowall\%3Dtrue\# (accessed on 7 December 2020). [CrossRef]

39. Camargo, L.M.; Collura, V.; Rain, J.-C.; Mizuguchi, K.; Hermjakob, H.; Kerrien, S.; Bonnert, T.P.; Whiting, P.; Brandon, N. Disrupted in Schizophrenia 1 interactome: Evidence for the close connectivity of risk genes and a potential synaptic basis for schizophrenia. Mol. Psychiatry 2007, 12, 74-86. [CrossRef] [PubMed]

40. Honer, W.G.; Falkai, P.; Bayer, T.A.; Xie, J.; Hu, L.; Li, H.-Y.; Arango, V.; Mann, J.J.; Dwork, A.J.; Trimble, W.S. Abnormalities of SNARE Mechanism Proteins in Anterior Frontal Cortex in Severe Mental Illness. Cereb. Cortex 2002, 12, 349-356. Available online: https:/ / academic.oup.com/cercor/article-lookup/doi/10.1093/cercor/12.4.349 (accessed on 30 November 2020). [CrossRef]

41. Mukaetova-Ladinska, E.; Hurt, J.; Honer, W.; Harrington, C.; Wischik, C. Loss of synaptic but not cytoskeletal proteins in the cerebellum of chronic schizophrenics. Neurosci. Lett. 2002, 317, 161-165. Available online: http://www.sciencedirect.com/ science/article/pii/S0304394001024582 (accessed on 7 December 2020). [CrossRef]

42. Martins-De-Souza, D.; Maccarrone, G.; Wobrock, T.; Zerr, I.; Gormanns, P.; Reckow, S.; Falkai, P.; Schmitt, A.; Turck, C.W. Proteome analysis of the thalamus and cerebrospinal fluid reveals glycolysis dysfunction and potential biomarkers candidates for schizophrenia. J. Psychiatr. Res. 2010, 44, 1176-1189. [CrossRef]

43. Saia-Cereda, V.M.; Cassoli, J.S.; Schmitt, A.; Falkai, P.; Nascimento, J.M.; Martins-De-Souza, D. Proteomics of the corpus callosum unravel pivotal players in the dysfunction of cell signaling, structure, and myelination in schizophrenia brains. Eur. Arch. Psychiatry Clin. Neurosci. 2015, 65, 601-612. [CrossRef] [PubMed]

44. Drago, F.; Lombardi, M.; Prada, I.; Gabrielli, M.; Joshi, P.; Cojoc, D.; Franck, J.; Fournier, I.; Vizioli, J.; Verderio, C. ATP modifies the proteome of extracellular vesicles released by microglia and influences their action on astrocytes. Front. Pharmacol. 2017, 8, 910. [CrossRef] [PubMed] 
45. Chen, S.-Y.; Huang, P.-H.; Cheng, H.-J. Disrupted-in-Schizophrenia 1-mediated axon guidance involves TRIO-RAC-PAK small GTPase pathway signaling. Proc. Natl. Acad. Sci. USA 2011, 108, 5861-5866. [CrossRef]

46. Friston, K.; Brown, H.R.; Siemerkus, J.; Stephan, K.E. The dysconnection hypothesis. Schizophr. Res. 2016, 176, 83-94. [CrossRef]

47. Wang, Z.; Li, P.; Wu, T.; Zhu, S.; Deng, L.; Cui, G. Axon guidance pathway genes are associated with schizophrenia risk. Exp. Ther. Med. 2018, 16, 4519-4526. [CrossRef]

48. Sayas, C.L.; Basu, S.; Van Der Reijden, M.; Bustos-Morán, E.; Liz, M.; Sousa, M.; van Ijcken, W.; Avila, J.; Galjart, N. Distinct Functions for Mammalian CLASP1 and -2 During Neurite and Axon Elongation. Front. Cell. Neurosci. 2019, 13, 1-17. [CrossRef]

49. Rajasekaran, A.; Venkatasubramanian, G.; Berk, M.; Debnath, M. Mitochondrial dysfunction in schizophrenia: Pathways, mechanisms and implications. Neurosci. Biobehav. Rev. 2015, 48, 10-21. [CrossRef] [PubMed]

50. Semendeferi, K.; Damasio, H. The brain and its main anatomical subdivisions in living hominoids using magnetic resonance imaging. J. Hum. Evol. 2000, 38, 317-332. Available online: https://www.sciencedirect.com/science/article/pii/S0047248499903 810 (accessed on 3 March 2021). [CrossRef]

51. Howarth, C.; Gleeson, P.; Attwell, D. Updated energy budgets for neural computation in the neocortex and cerebellum. J. Cereb. Blood Flow Metab. 2012, 32, 1222-1232. [CrossRef] [PubMed]

52. Nopoulos, P.; Ceilley, J.W.; Gailis, E.A.; Andreasen, N.C. An MRI study of cerebellar vermis morphology in patients with schizophrenia: Evidence in support of the cognitive dysmetria concept. Biol. Psychiatry 1999, 46, 703-711. [CrossRef]

53. Koziol, L.F.; Budding, D.; Andreasen, N.; D’Arrigo, S.; Bulgheroni, S.; Imamizu, H.; Ito, M.; Manto, M.; Marvel, C.; Parker, K.; et al. Consensus paper: The cerebellum's role in movement and cognition. Cerebellum 2014, 13, 151-177. [CrossRef]

54. Verge, B.; Alonso, Y.; Valero, J.; Miralles, C.; Vilella, E.; Martorell, L. Mitochondrial DNA (mtDNA) and schizophrenia. Eur. Psychiatry 2011, 26, 45-56. [CrossRef] [PubMed]

55. Prabakaran, S.; Swatton, J.E.; Ryan, M.M.; Huffaker, S.J.; Huang, J.; Griffin, J.L.; Wayland, M.; Freeman, T.; Dudbridge, F.; Lilley, K.S.; et al. Mitochondrial dysfunction in schizophrenia: Evidence for compromised brain metabolism and oxidative stress. Mol. psychiatry 2004, 9, 684-697. [CrossRef] [PubMed]

56. Maurer, I.; Zierz, S.; Möller, H.J. Evidence for a mitochondrial oxidative phosphorylation defect in brains from patients with schizophrenia. Schizophr. Res. 2001, 48, 125-136. [CrossRef]

57. Roberts, R.C. Postmortem studies on mitochondria in schizophrenia. Schizophr. Res. 2017, 187, 17-25. [CrossRef] [PubMed]

58. Zuccoli, G.S.; Saia-Cereda, V.M.; Nascimento, J.; Martins-De-Souza, D. The energy metabolism dysfunction in psychiatric disorders postmortem brains: Focus on proteomic evidence. Front. Neurosci. 2017, 11, 493. [CrossRef]

59. Martins-De-Souza, D.; Gattaz, W.F.; Schmitt, A.; Novello, J.C.; Marangoni, S.; Turck, C.W.; Dias-Neto, E. Proteome analysis of schizophrenia patients Wernicke's area reveals an energy metabolism dysregulation. BMC Psychiatry 2009, 9, 17. [CrossRef]

60. English, J.A.; Pennington, K.; Dunn, M.J.; Cotter, D.R. The Neuroproteomics of Schizophrenia. Biol. Psychiatry 2011, 69, 163-172. [CrossRef]

61. Bubber, P.; Hartounian, V.; Gibson, G.; Blass, J. Abnormalities in the tricarboxylic acid (TCA) cycle in the brains of schizophrenia patients. Eur. Neuropsychopharmacol. 2011, 21, 254-260. [CrossRef]

62. Martins-De-Souza, D.; Harris, L.; Guest, P.; Bahn, S. The role of energy metabolism dysfunction and oxidative stress in schizophrenia revealed by proteomics. Antioxid. Redox Signal. 2011, 15, 2067-2079. [CrossRef] [PubMed]

63. Rollins, B.L.; Morgan, L.; Hjelm, B.E.; Sequeira, A.; Schatzberg, A.F.; Barchas, J.D.; Lee, F.S.; Myers, R.M.; Watson, S.J.; Akil, H.; et al. Mitochondrial Complex I Deficiency in Schizophrenia and Bipolar Disorder and Medication Influence. Mol. Neuropsychiatry 2017, 3, 157-169. [CrossRef] [PubMed]

64. De Oliveira, S.; Rosowski, E.E.; Huttenlocher, A. Neutrophil migration in infection and wound repair: Going forward in reverse. Nat. Rev. Immunol. 2016, 16, 378-391. [CrossRef]

65. Kinney, D.K.; Hintz, K.; Shearer, E.M.; Barch, D.H.; Riffin, C.; Whitley, K.; Butler, R. A unifying hypothesis of schizophrenia: Abnormal immune system development may help explain roles of prenatal hazards, post-pubertal onset, stress, genes, climate, infections, and brain dysfunction. Med. Hypotheses 2010, 74, 555-563. [CrossRef] [PubMed]

66. McKinnon, C.M.; Mellor, H. The tumor suppressor RhoBTB1 controls Golgi integrity and breast cancer cell invasion through METTL7B. BMC Cancer. 2017, 17, 145. [CrossRef]

67. Kim, S.; Choi, K.H.; Baykiz, A.F.; Gershenfeld, H.K. Suicide candidate genes associated with bipolar disorder and schizophrenia: An exploratory gene expression profiling analysis of post-mortem prefrontal cortex. BMC Genom. 2007, 8, 413. [CrossRef]

68. Föcking, M.; Lopez, L.; A English, J.; Dicker, P.; Wolff, A.; Brindley, E.; Wynne, K.; Cagney, G.; Cotter, D. Proteomic and genomic evidence implicates the postsynaptic density in schizophrenia. Mol. Psychiatry 2015, 20, 424-432. [CrossRef]

69. Scarr, E.; Udawela, M.; A Thomas, E.; Dean, B. Changed gene expression in subjects with schizophrenia and low cortical muscarinic M1 receptors predicts disrupted upstream pathways interacting with that receptor. Mol. Psychiatry 2018, 23, 295-303. [CrossRef]

70. Gardner, D.M.; Murphy, A.L.; O’Donnell, H.; Centorrino, F.; Baldessarini, R.J. International consensus study of antipsychotic dosing. Am. J. Psychiatry 2010, 167, 686-693. [CrossRef]

71. Pinacho, R.; Villalmanzo, N.; Lalonde, J.; Haro, J.M.; Meana, J.J.; Gill, G.; Ramos, B. The transcription factor SP4 is reduced in postmortem cerebellum of bipolar disorder subjects: Control by depolarization and lithium. Bipolar Disord. 2011, 13, 474-485. [CrossRef] 
72. Yosef, B.Y.; Hochberg, Y. Controlling the False Discovery Rate: A Practical and Powerful Approach to Multiple Testing. J. R. Stat. Soc. Ser. B 1995, 57, 289-300.

73. Tyanova, S.; Temu, T.; Sinitcyn, P.; Carlson, A.; Hein, M.Y.; Geiger, T.; Mann, M.; Cox, J. The Perseus computational platform for comprehensive analysis of (prote)omics data. Nat. Methods 2016, 13, 731-740. [CrossRef]

74. Wu, Y.; Yao, Y.-G.; Luo, X.-J. SZDB: A Database for Schizophrenia Genetic Research. Schizophr. Bull. 2017, 43, 459-471. [CrossRef]

75. Pathan, M.; Keerthikumar, S.; Ang, C.-S.; Gangoda, L.; Quek, C.; Williamson, N.; Mouradov, D.; Sieber, O.; Simpson, R.; Salim, A.; et al. FunRich: An open access standalone functional enrichment and interaction network analysis tool. Proteomics 2015, 15, 2597-2601. [CrossRef]

76. Hewett, M.; Oliver, D.E.; Rubin, D.L.; Easton, K.L.; Stuart, J.M.; Altman, R.B.; Altman, R.B.; Klein, T.E. BiGCaT Bioinformatics $\backslash$ rPharmGKB: The Pharmacogenetics Knowledge Base. Nucleic Acids Res. 2002, 30, $163-165$. Available online: http:/ / www.bigcat.nl (accessed on 7 March 2021). [CrossRef]

77. Jourquin, J.; Duncan, D.; Shi, Z.; Zhang, B. GLAD4U: Deriving and prioritizing gene lists from PubMed literature. BMC Genom. 2012, 13 (Suppl. 8), S20. Available online: http://www.biomedcentral.com/1471-2164/13/S8/S20 (accessed on 20 December 2020). [CrossRef] [PubMed]

78. Szklarczyk, D.; Gable, A.L.; Lyon, D.; Junge, A.; Wyder, S.; Huerta-Cepas, J.; Simonovic, M.; Doncheva, N.T.; Morris, J.H.; Bork, P.; et al. STRING v11: Protein-protein association networks with increased coverage, supporting functional discovery in genome-wide experimental datasets. Nucleic Acids Res. 2019, 47, 607-613. [CrossRef]

79. Uhlén, M.; Fagerberg, L.; Hallström, B.M.; Lindskog, C.; Oksvold, P.; Mardinoglu, A.; Sivertsson, Å.; Kampf, C.; Sjöstedt, E.; Asplund, A.; et al. Tissue-based map of the human proteome. Science 2015, 347, 1260419.

80. Bailoo, J.D.; Varholick, J.A.; Garza, X.J.; Jordan, R.L.; Hintze, S. Maternal separation followed by isolation-housing differentially affects prepulse inhibition of the acoustic startle response in C57BL/6 mice. Dev. Psychobiol. 2016, 58, 937-944. [CrossRef] [PubMed]

81. Van Zyl, P.J.; Dimatelis, J.J.; Russell, V.A. Behavioural and biochemical changes in maternally separated Sprague-Dawley rats exposed to restraint stress. Metab. Brain Dis. 2016, 31, 121-133. [CrossRef] 